\title{
Model uncertainties in climate change impacts on Sahel precipitation in ensembles of CMIP5 and CMIP6 simulations
}

\author{
Paul-Arthur Monerie $^{1}$ (D) $\cdot$ Caroline M. Wainwright ${ }^{1}$ (D) $\cdot$ Moussa Sidibe $^{2} \cdot$ Akintomide Afolayan Akinsanola $^{3}$ (D)
}

Received: 6 November 2019 / Accepted: 11 June 2020 / Published online: 20 June 2020

(c) The Author(s) 2020

\begin{abstract}
The impact of climate change on Sahel precipitation suffers from large uncertainties and is strongly model-dependent. In this study, we analyse sources of inter-model spread in Sahel precipitation change by decomposing precipitation into its dynamic and thermodynamic terms, using a large set of climate model simulations. Results highlight that model uncertainty is mostly related to the response of the atmospheric circulation to climate change (dynamic changes), while thermodynamic changes are less uncertain among climate models. Uncertainties arise mainly because the models simulate different shifts in atmospheric circulation over West Africa in a warmer climate. We linked the changes in atmospheric circulation to the changes in Sea Surface Temperature, emphasising that the Northern hemispheric temperature gradient is primary to explain uncertainties in Sahel precipitation change. Sources of Sahel precipitation uncertainties are shown to be the same in the new generation of climate models (CMIP6) as in the previous generation of models (CMIP5).
\end{abstract}

Keywords Uncertainties $\cdot$ Climate models $\cdot$ West Africa $\cdot$ Projected changes $\cdot$ Atmospheric circulation

\section{Introduction}

In Sahelian countries, around 65\% of the labour force (FAO, 2006) and 95\% of the land use (Rockström et al. 2004) are devoted to agriculture, which is predominantly rain-fed. About one-third of the gross domestic product depends on the agricultural sector, versus about $14 \%$ for developed nations. The monsoon season occurs between late June to late September (Liebmann et al. 2012; Dunning et al. 2016; Akinsanola and Zhou 2019a) and brings about $80 \%$ of the annual rainfall amount. As a result, the Sahelian countries are highly vulnerable to intraseasonal and multidecadal

Electronic supplementary material The online version of this article (https://doi.org/10.1007/s00382-020-05332-0) contains supplementary material, which is available to authorized users.

Paul-Arthur Monerie

pmonerie@gmail.com

1 National Centre for Atmospheric Science, University of Reading, Reading, UK

2 Centre for Agroecology, Water and Resilience (CAWR), Coventry University, Coventry, UK

3 Department of Geography, University of Georgia, Athens, Georgia, USA variability of the West African Monsoon. It has been shown that climate change could have robust impacts on agriculture yield (Sultan et al. 2014; Sultan and Gaetani 2016), river flow (Angelina et al. 2015; Aich et al. 2016; Stanzel et al. 2018; Sylla et al. 2018; Sidibe et al. 2020) and extreme precipitation events (Sylla et al. 2015; Han et al. 2019; Akinsanola and Zhou 2019a) over West Africa. However, projections for the end of the 21st century suffer from large uncertainties (Biasutti 2013; Monerie et al. 2016; Yan et al. 2018), with some models simulating an increase in precipitation while others simulates a decrease in precipitation alongside strong differences in precipitation change patterns over West Africa.

Studies have demonstrated that a pattern in precipitation change emerges in a warmer climate, with more severe drought conditions over the western Sahel and an increase in precipitation over the central Sahel (Fontaine et al. 2011; Monerie et al. 2012, 2016; Biasutti 2013; James et al. 2015; Dunning et al. 2018; Akinsanola and Zhou 2019c; among others). There is an agreement about the pattern of precipitation change for short-term (i.e. 2010-2049), near-term (i.e. 2045-2070) and long-term (i.e. end of the 21st Century) time horizons under medium RCP4.5 (Monerie et al. 2013) and high RCP8.5 (Monerie et al. 2017; Akinsanola and Zhou 2018) emissions scenario. However, no consensus can be 
found regarding the magnitude of precipitation change over the Sahel (Solomon et al. 2007; Barros et al. 2014), as stated by the third and fifth assessment reports of the IPCC.

Precipitation variability can be associated with changes in the strength and direction of the wind (i.e. dynamic changes), the availability of specific humidity in the boundary layer (i.e. thermodynamic changes), and changes in both the atmospheric dynamic and specific humidity (see for instance Akinsanola and Zhou 2019b, c). In a warmer climate, we can thus expect uncertainties in simulating both dynamical and thermodynamic changes to contribute to the total uncertainty in precipitation change across climate models.

Sahel precipitation variability is associated with variability of the sea surface temperature (SST) on interannual to multi-decadal time scales (Folland et al. 1986; Palmer 1986; Rowell et al. 1992; Mohino et al. 2011; Martin and Thorncroft 2014). The warming of the tropical SSTs also impacts the global Hadley cell circulation (Ma et al. 2011, 2018), hence imposing stability and reducing precipitation over the tropics and West Africa. Changes in SSTs could impact Sahel precipitation by shifting atmospheric circulation patterns over West Africa and allowing evaporation to increase over the ocean (Monerie et al. 2019). Therefore, inter-model differences in SST change, and in SST-Sahel precipitation teleconnections, are strong sources of uncertainty in Sahel precipitation change (Giannini et al. 2013; Park et al. 2015, 2016; Gaetani et al. 2017).

Reducing uncertainties is of primary importance for providing useful information to policymakers. A common way to deal with large uncertainties is to select an ensemble of the best models, as defined from the model's ability to simulate the historical climate, with regard to observations/ reanalysis (Cook and Vizy 2006; Lee and Wang 2014). The underlying rationale is that models that are able to reproduce the observed climate variability and the mean state could perform better at projecting future climate. However, this is not straightforward. Firstly, although model ranking was found to be highly variable dependent (Santer et al. 2009; Monerie et al. 2012), best models selection are often solely based on surface variable evaluation, e.g. precipitation. Secondly, findings from previous studies suggest that there is no clear relationship between model's ability to simulate observed climate and precipitation projections (Monerie et al. 2016; Yan et al. 2018). Reducing uncertainties is therefore not straightforward and would benefit from a better understanding of the inter-model spread in precipitation change. Here, we take a step forward into understanding the uncertainties in Sahel precipitation change. This could help scientists to improve robustness of the projections, providing a better information to policymakers. Changes in precipitation are complex since they are not only associated with changes in moisture availability described by the
Clausius-Clapeyron relation, but also with the modulation of the strength of the tropical mean circulation, as well as shifts in atmospheric circulation (Chadwick et al. 2013). Our approach is based on a simple framework for precipitation decomposition described in (Chadwick et al. 2013, 2016; Rowell and Chadwick 2018). Although, Kent et al. (2015) and Chadwick et al. (2016) have analysed changes in precipitation on a global scale, as shown by multi model mean, we aim at investigating the model uncertainties in precipitation change, over the Sahel.

In this study, we use a set of CMIP5 simulations (Taylor et al. 2012) along with a set of the newly developed Climate Model Intercomparison Project Phase-6 (CMIP6) simulations (Eyring et al. 2016). The aim of the paper is twofold. Firstly, to investigate sources of precipitation uncertainties over the Sahel, focusing on inter-model difference. Secondly, to assess the ability of the new generation of climate models (CMIP6) to simulate mean summer Sahel precipitation, relative to the previous generation of models (CIMP5), and to analyse changes in Sahel precipitation in both CMIP simulations. This study could provide useful information on the causes of the inter-model spread in projected Sahel precipitation change and how these uncertainties could be reduced.

\section{Data and method}

\subsection{Data}

The fifth phase of the Climate Model Intercomparison Project (CMIP5; Taylor et al. 2012) allows us to analyse discrepancies in Sahel precipitation change in a large number of simulations. We use the outputs of 29 CMIP5 models. Therefore, we evaluate how models diverge in projecting long-term impacts of climate change over the Sahel, using a high emission scenario. Precipitation changes are analysed for the main period of the Sahel rainy season, from July to September (hereafter noted JAS). The focus is on quantifying the response of Sahel precipitation to an increase in well-mixed greenhouse gases by computing the difference between the period 2060-2099, under the RCP8.5 emission scenario, to the reference period 1960-1999, under the historical emission scenario. In addition, we use a set of 11 CMIP6 simulations, the new generation of climate models (Eyring et al. 2016), which was available at the time of the study, using both the historical, and the ssp585 emission scenario, which is close to the RCP8.5 emission scenario (O'Neill et al. 2016). At the end of the 21st century, uncertainties due to how models simulate internal climate variability is moderate in comparison to uncertainties related to model's formulations (Monerie et al. 2017a; Fig. 1c, d). Therefore, we use the first available member for each CMIP5 
(a) CMIP5 bias

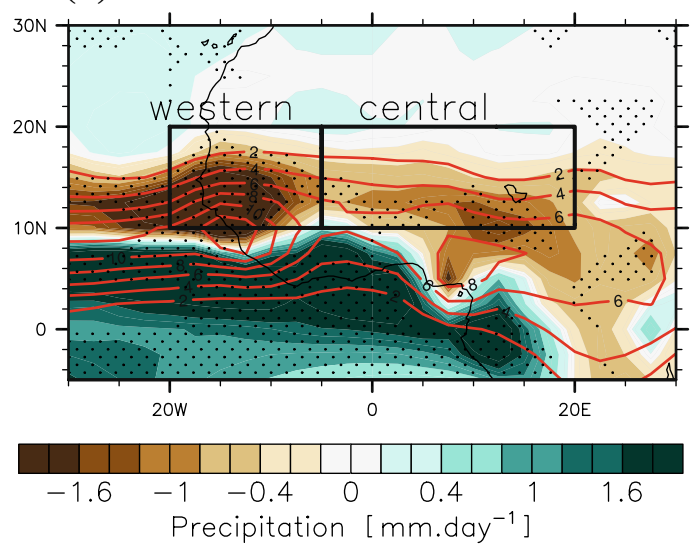

(c) Mean bias

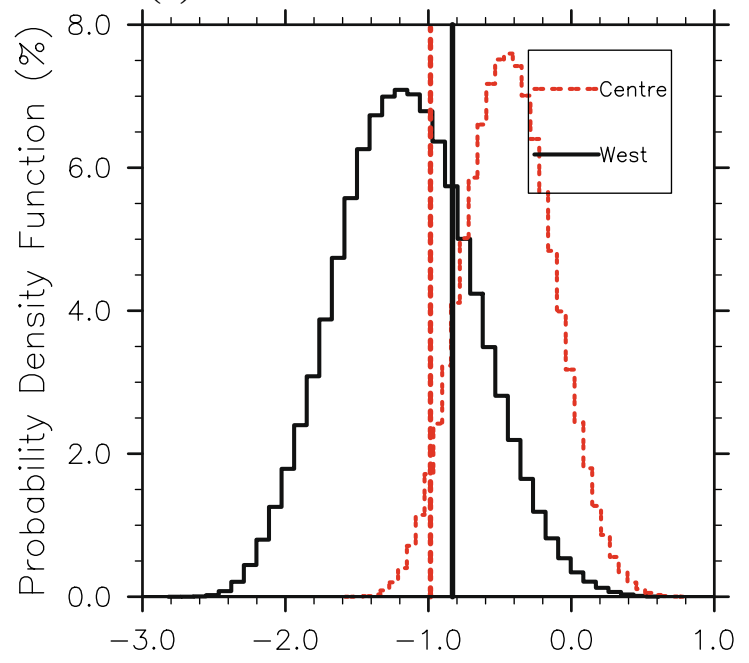

Fig. 1 a CMIP5 multi-model mean change in precipitation as obtained by the difference between the period 2060-2099 (rcp8.5 emission scenario) minus the period 1960-1999 (historical emission scenario), for JAS. The red contours show the multi-mean mean historical precipitation (from 0 to $16 \mathrm{~mm} \mathrm{day}^{-1}$, every $2 \mathrm{~mm} \mathrm{day}^{-1}$ ). b same as a but for the CMIP6 multi-model mean precipitation and with the historical and ssp585 emission scenarios. Stippling indicates that at least $70 \%$ of the models agree on the sign of the multi-mode mean precipitation change. Inter-model spread in precipitation change (colour) with the inter-model spread in historical precipitation (contour) for the c CMIP5 and d CMIP6 simulations. Stippling indicates that uncertainty due to model formulation account for at least $80 \%$ of the total uncertainty (see the text for further information). e Change

and CMIP6 model and assume that our results are not sensitive to the ensemble-member size.

To evaluate biases in precipitation we use the data of the Global Precipitation Climatology Project (GPCP; Adler et al. 2003) that is available from 1979 to present on a $2.5^{\circ}$ global grid. GPCP uses data from rain gauge stations, satellites, and sounding observations, which have been merged to estimate monthly precipitation. Data of the Global Precipitation Climatology Centre (GPCC; Schneider et al. 2014b) has

\section{(b) CMIP6 bias}

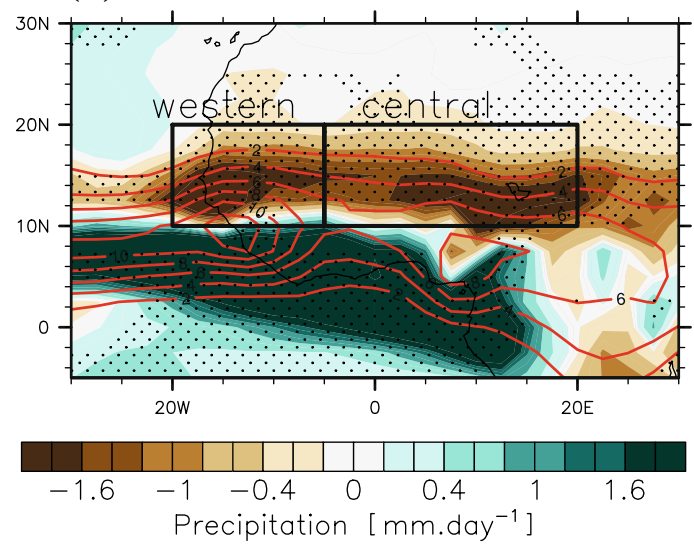

(d) Spread bias

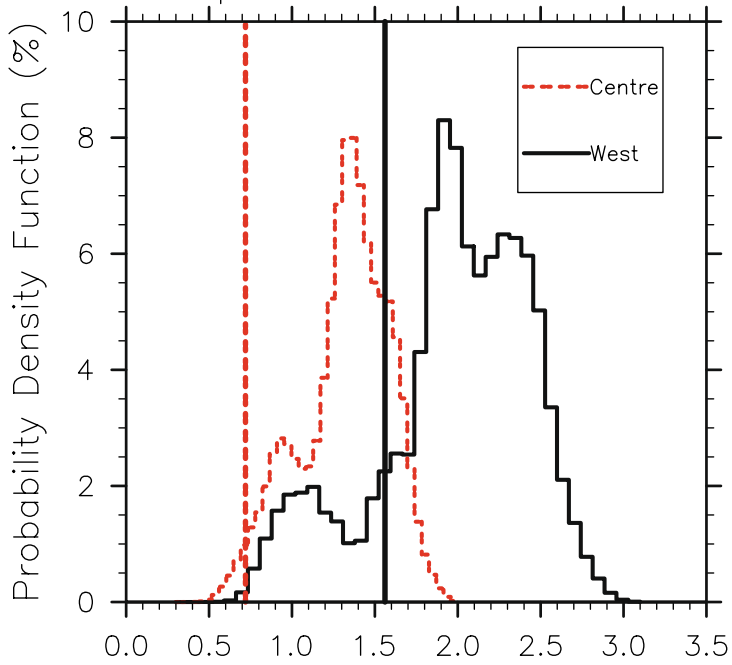

in precipitation for each model over the Western [10-20 N; 20-5 W; "W"] and the central [10- $20 \mathrm{~N}$; 5W-20E; "C"] Sahel (see the boxes on the panel a). The grey shading indicates the inter-model standard deviation and the cross the multi-model mean average in precipitation change. CMIP5 simulations (" 5 ") are represented by a filled circle while CMIP6 simulations ("6") are represented by an empty square. f Probability density function as obtained from a set of 3 million of randomly computed ensemble of 11 CMIP5 multi-model mean precipitation change for the western Sahel precipitation (black line) and the central Sahel precipitation (red line). The vertical lines indicate the multi-model mean precipitation change as obtained from the set of 11 CMIP6 simulations

also been used to verify how results vary with reference to another observational data set.

\subsection{Method}

Changes and variability in precipitation are associated with dynamic and thermodynamic changes. We assume that uncertainties related to these components might impact simulations of total precipitation. Thus, to better 
understand sources of uncertainties among the CMIP5 and CMIP6 ensembles, precipitation is decomposed into several terms, following (Chadwick et al. 2013, 2016). Held and Soden (2006) assumed that precipitation can be approximated by,

$P=M^{*} q$ and $\Delta P=\Delta\left(M^{*} q\right)$

where, $\mathrm{P}$ is precipitation, $\mathrm{M}^{*}$ is a proxy for convective massflux from the boundary layer to the free troposphere (with $\mathrm{M}^{*}=\mathrm{P} / \mathrm{q}$ ), and $\mathrm{q}$ is the near surface specific humidity. Thus, high precipitation rates imply large convective mass flux when convection is pumping up low specific humidity air from the boundary layer. This method relies on the fact that tropical precipitation is dominated by convection (Chadwick et al. 2016; Rowell and Chadwick 2018). $\Delta$ indicates changes associated with climate change, which is the difference between the end of 21 st century and historical periods.

Precipitation change is then reformulated in terms of thermodynamic $\left(\Delta P_{\text {therm }}\right.$, dynamic $\left(\Delta P_{d y n}\right)$ and cross nonlinear $\left(\Delta P_{\text {cross }}\right)$ components.

$\Delta P=M^{*} \Delta q+q \Delta M^{*}+\Delta q \Delta M^{*}$

$\Delta P=\Delta P_{\text {therm }}+\Delta P_{d y n}+\Delta P_{\text {cross }}$

where $\Delta P_{d y n}$ is the change in precipitation due to a change in the atmospheric circulation (dynamic term), $\Delta P_{\text {therm }}$ is the change in precipitation due to a change in specific humidity availability (thermodynamic term) and $\Delta P_{\text {cross }}$ is the change in precipitation due to changes in both atmospheric circulation and specific humidity.

Further decomposition of $\Delta P_{d y n}$ allows one to document changes that are due to the weakening of the tropical mean circulation $\left(\Delta P_{\text {weak }}\right)$ and to a shift in the pattern of the circulation $\left(\Delta P_{\text {shift }}\right)$, as

$\Delta P_{\text {weak }}=q \Delta M_{\text {weak }}^{*}$

$\Delta P_{\text {shift }}=q \Delta M_{\text {shift }}^{*}$

with,

$\Delta M_{\text {weak }}^{*}=-\alpha M^{*}$

where.

$\alpha=-\left(\right.$ tropical mean $\Delta M^{*} /$ tropical mean $\left.M^{*}\right)$

$\alpha$ is scaled by the strength of the mean tropical circulation, suggesting that changes in the tropical mean circulation is inversely proportional to the climatology mass-flux field, as stated in (Chadwick et al. 2013). The tropical mean is the weighted area average, computed between $30^{\circ}$ $\mathrm{S}$ and $30^{\circ} \mathrm{N}$.
Finally,

$\Delta M_{\text {shift }}^{*}=\Delta M^{*}-\Delta M_{\text {weak }}^{*}$

The decomposition is performed using monthly means (Kent et al. 2015; Chadwick et al. 2016; Rowell and Chadwick 2018) before computing the seasonal means and the area-weighted averages (i.e. western and central Sahel). This decomposition allows understanding the drivers of precipitation change and uncertainties, in terms of dynamic and thermodynamic changes. Besides, it allows decomposing dynamic changes, by showing the effects of climate change on the weakening of the tropical mean circulation and on patterns in atmospheric circulation. These cannot be assessed using other decomposition method, such as, the decomposition presented in Seager et al. (2014).

\section{Results}

\subsection{Simulation of historical observed precipitation}

During the rainy season (JAS) the maximum precipitation occurs at $10^{\circ} \mathrm{N}$ and decreases as we move north and south (Fig. 2a). Peaks in observed precipitation are located over the mountains of Guinea Coast and the Cameroon highlands. CMIP5 climate models underestimate Sahel precipitation and overestimate precipitation over the Guinea Coast and the tropical Atlantic Ocean (Fig. 2a). In CMIP5 simulations the monsoon system does not propagate far enough northward and precipitation over the Sahel is underestimated. This dry bias is systematic over the Sahel and is associated with a cold bias over the Sahara and a warm bias over the Atlantic cold tongue, as also reported in (Richter et al. 2012; Roehrig et al. 2013; Foltz et al. 2019; Fig. S1). The new generation of models (CMIP6) also produces an anomalously southward shifted monsoon system and underestimates Sahel precipitation (Fig. 2b). The same conclusion is obtained when evaluating bias in precipitation against GPCC (Schneider et al. 2014b) (not shown).

Over the central Sahel, precipitation biases are higher in the set of CMIP6 simulations than in the set of CMIP5 simulations. However, comparing a set of 29 simulations to a set of 11 simulations is not robust since simulated Sahel precipitation is strongly model dependent (Druyan 2011) and a reduced set of models is more likely to be impacted by outlier simulations. We randomly resampled the set of CMIP5 simulations to obtain a large number of 11-model ensembles. Then we can ascertain whether the difference in bias is due to the ensemble size or not. For the western Sahel, result shows that the difference in the bias is related to ensemble size (Fig. 2c). However, we find, for the central Sahel, that the CMIP6 bias is stronger than $90 \%$ of the 
(a) $\triangle \mathrm{P}$ CMIP5 mean

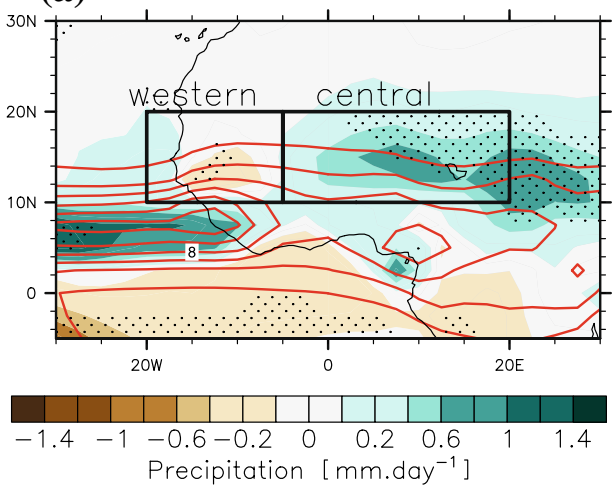

(c) $\triangle \mathrm{P}$ CMIP5 spread

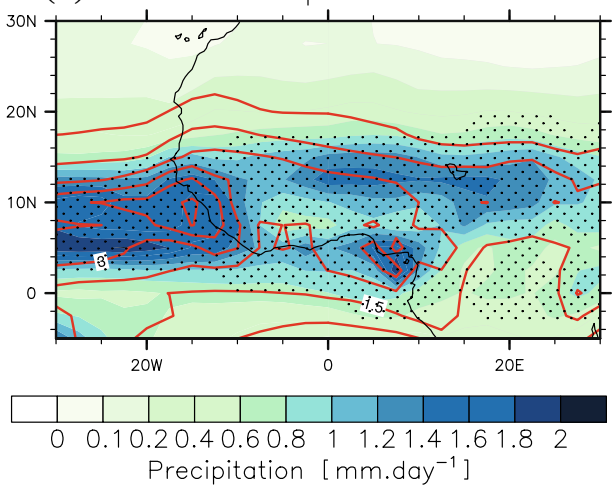

(e) $\Delta P$ West \& Central Sahel

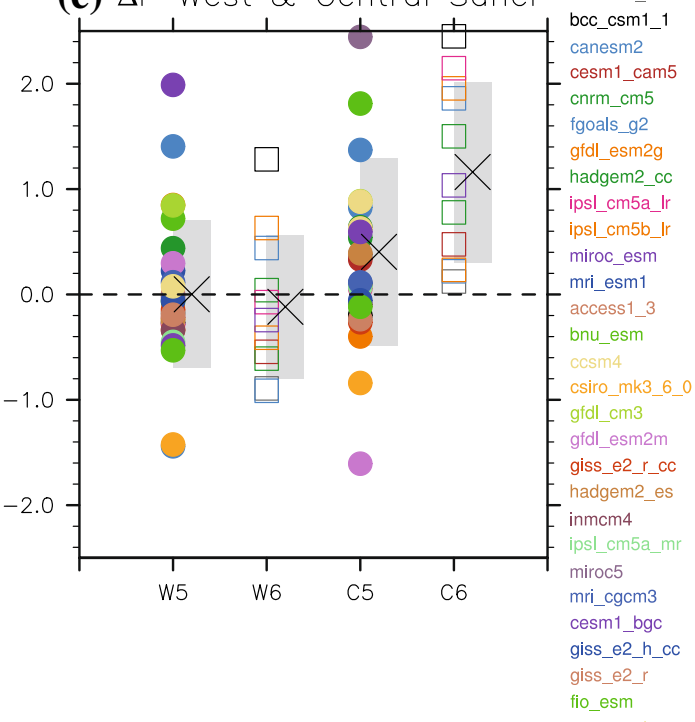

Fig. 2 Multi-model mean precipitation biases in JAS for a set of a 29 CMIP5 simulations and b 11 CMIP6 simulations. Biases (shadings) are computed as the difference between the JAS mean historical simulations (period 1979-1999) minus the JAS mean observed precipitation (period 1979-1999; GPCC). On a and b the red contours indicate the climatological JAS observed precipitation (from 0 to $16 \mathrm{~mm}$ day $^{-1}$, every $2 \mathrm{~mm} \mathrm{day}^{-1}$ ). Stippling indicate that at least $70 \%$ of the models agree on the sign of the multi-model mean bias. Probability (b) $\triangle \mathrm{P}$ CMIP6 mean

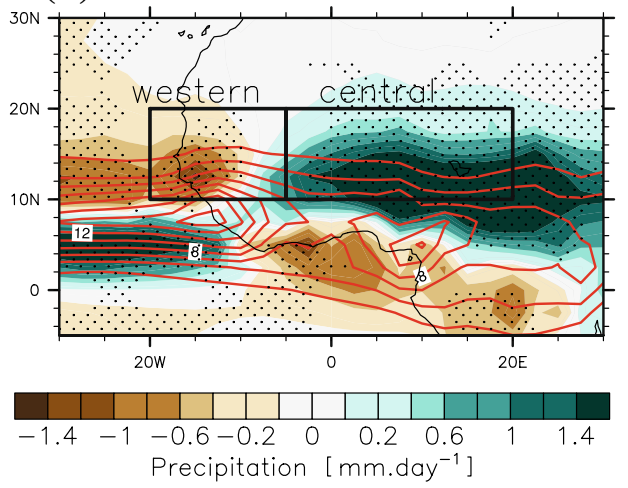

(d) $\triangle \mathrm{P}$ CMIP6 spread

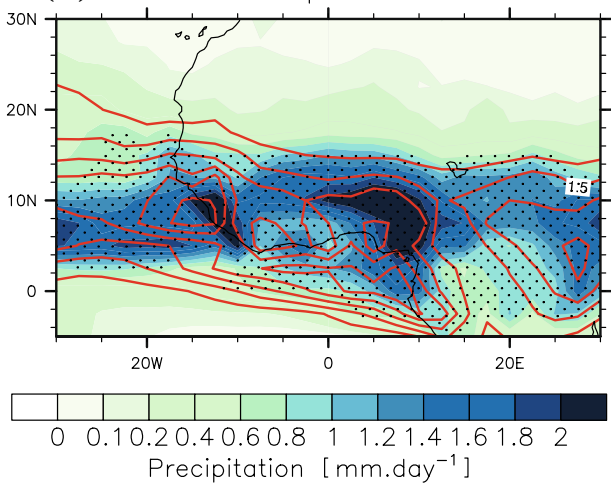

(f) Mean change

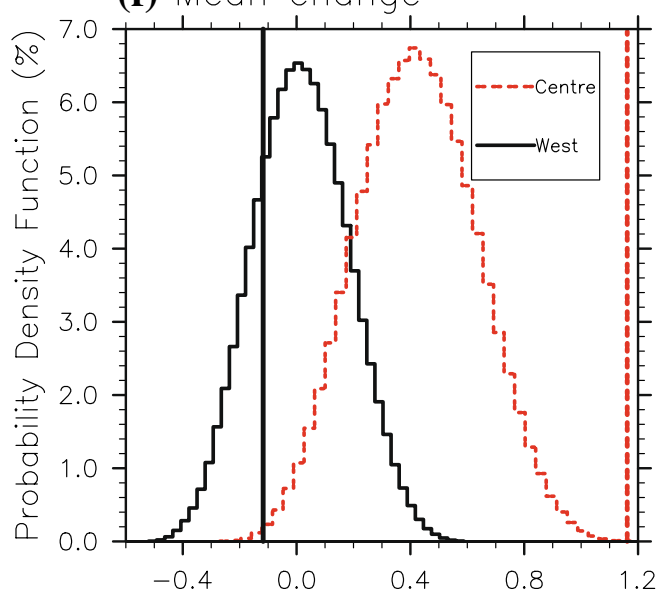

density function as obtained from a set of 3 million of randomly computed ensemble of 11 CMIP5 $\mathbf{c}$ multi-model mean bias and $\mathbf{d}$ intermodel bias spread for the western Sahel precipitation (black line) and the central Sahel precipitation (red line). On panels $\mathbf{c}$ and $\mathbf{d}$, the vertical lines indicate the multi-model mean bias and the inter-model spread in precipitation biases, as obtained from the set of 11 CMIP6 simulations 
resampled 11 CMIP5 model ensembles. Therefore, there is a high probability that the dry bias is stronger in the CMIP6 than in the CMIP5 simulations over the central Sahel. Thus, the new generation of models does not necessarily perform better than the older generation of models.

The inter-model spread, i.e. the divergence between the model's simulations, is weaker within the CMIP6 than within the CMIP5 ensemble (Fig. 2d). However, a reduced inter-model spread is only significant (at the $90 \%$ confidence level with a two-sided test) for the central Sahel precipitation. Therefore, over the central Sahel, there is an agreement in the CMIP6 simulations on an increase in the dry bias, relative to the CMIP5 ensemble.

Outlier models could lead to strong changes in the multimodel mean precipitation bias and the inter-model spread. Therefore, we displayed the bias for each model for the western and central Sahel precipitation but did not find strong evidences to discard one or a group of particular models (Fig. S2).

\subsection{Future changes in precipitation}

Precipitation is projected to increase over the central Sahel and to decrease over the western Sahel, as noted in many studies (Fontaine et al. 2011; among others) (Fig. 1a). There is an agreement among the CMIP5 models on the sign of the central Sahel precipitation change, while the decrease in western Sahel precipitation is reproduced by a smaller number of models (see the shadings on the Fig. 1a). Changes in the sign of precipitation are thus more uncertain over the western than over the central Sahel in this CMIP5 ensemble. The multi-model mean change in precipitation is moderate in comparison to the inter-model spread in precipitation change (Fig. 1c, d), highlighting strong uncertainties in Sahel precipitation change at the end of the 21 st century. We show, within Fig. S3 that precipitation change is only significant over the central Sahel within the CMIP5 ensemble.

Interestingly, there is a strong spread in simulating historical precipitation among the CMIP5 models (see the red contours in Fig. 1c); improving model's ability to simulate historical observed climate could thus lead to a reduced divergence in model's projections. However, Monerie et al. (2016) and Yan et al. (2018) have shown that linking biases in observed mean precipitation and temperature with projections of Sahel precipitation is not straightforward. This is discussed later.

CMIP6 simulations reproduce the CMIP5 pattern in precipitation change, with an increase in precipitation over the central Sahel and a decrease in precipitation over the western Sahel (Fig. 1b). Over the western (central) Sahel the tropical rain belt shifts southward (northward) (Fig. 1b), indicating strong changes in the monsoon circulation. The increase in precipitation is significantly stronger for the CMIP6 than for the CMIP5 simulations (Fig. 1f). The comparison of the CMIP5 probability density function to the CMIP6 multimean indicates that changes in central Sahel precipitation are significantly stronger in the CMIP6 than in the CMIP5 ensemble. Stronger changes in precipitation might arise from a change in the climate sensitivity between the CMIP6 and CMIP5 models (Gettelman et al. 2019), and to a slightly warmer climate in the CMIP6 than in the CMIP5 models (Fig. S4). For western Sahel precipitation, no statistically significant differences are noticeable between CMIP5 and CMIP6 simulations (Fig. 1f).

Unlike the CMIP5 models, the CMIP6 model's agreement is high over both the central and the western Sahel, when considering the sign in precipitation change (Fig. 1b). However, the inter-model spread in precipitation change is also strong in the CMIP6 ensemble, showing that Sahel precipitation uncertainties are unlikely to be reduced (Fig. 1d). Unlike CMIP5 models, precipitation change is significant over both the central and western Sahel within the CMIP6 ensemble (Fig. S3).

Changes in precipitation averaged over the central and the western Sahel, are displayed on Fig. 1e (for each model, the multi-model mean and the inter-model spread), and indicate that the impact of climate change is highly uncertain for Sahel precipitation. Over the western Sahel, the multi-model mean change in precipitation is close to zero with values ranging from $\sim-1.5 \mathrm{~mm} \mathrm{day}^{-1}$ to $+2.0 \mathrm{~mm} \mathrm{day}^{-1}$ for each individual model. Over the central Sahel, the inter-model spread is also high and results are strongly model-dependent. The inter-model spread is slightly stronger over the central than over the western Sahel. Unlike for CMIP5 models, the 11 CMIP6 models agree on an increase in precipitation over the central Sahel.

We compare model uncertainty to uncertainty due to natural (unforced) variations of 40-year mean anomalies, following (Rowell 2012). The uncertainty due to natural variations, $\sigma_{\triangle P_{-} N A T}^{2}$, is computed from the pre-industrial control runs as the multi-model mean 40-year anomaly precipitation variance of each model. The total uncertainty, $\sigma_{\triangle P}^{2}$ MODEL is the inter-model variance in precipitation change. Uncertainty due to model formulation is computed as a residual of the uncertainty due to natural variations from the total uncertainty, $\sigma_{\triangle P \_M O D E L}^{2}=\sigma_{\triangle P}^{2}-\sigma_{\triangle P N N A T}^{2}$. In Fig. 1c, d, the stippling show that the $\sigma_{\triangle P \_M O D E L}^{2} / \sigma_{\triangle P}^{2}$ ratio is higher than $80 \%$, showing that over most of the monsoon domain, model uncertainty is dominant and that the inter-model spread is unlikely to be due to uncertainty due to the simulation of the natural variations of Sahel precipitation.

\subsection{Dynamic and thermodynamic changes}

Changes in precipitation are associated with changes in specific humidity (i.e. thermodynamic changes), with 
changes in atmospheric circulation (i.e. dynamic changes), and with changes in both specific humidity and winds (i.e. the cross non-linear term); therefore we have decomposed precipitation into three terms, following Chadwick et al. (2016) (see Sect. 2.2).

Uncertainties are high for the dynamic component (Fig. 3b) and moderate for the thermodynamic and the cross-term components (Fig. 3a, c). Uncertainties in $\Delta P$ are thus dominated by differences in projected $\Delta P_{d y n}$, i.e. uncertainties mainly come from differences among models in simulated changes in atmospheric circulation.

The different terms are leading to precipitation changes of different signs and magnitudes. Thermodynamic changes are associated with an increase in precipitation (Fig. 3d) while dynamic changes are associated, on average, with a decrease in precipitation over the western and central Sahel in the set of CMIP5 simulations and western Sahel in CMIP6 simulations (Fig. 3e). Dynamic changes are associated with an increase in precipitation over the central Sahel in CMIP6 simulations. The cross term $\left(\Delta P_{\text {cross }}\right)$ is only leading to moderate changes and its inter-model spread is low compared to $\Delta P_{\text {therm }}$ and $\Delta P_{d y n}$ (Fig. 3f). Please note that precipitation changes, associated with each precipitation component, and each grid point, are shown in Figs. S5 and . S6.

Interestingly, models disagree on the sign of $\Delta P_{d y n}$ while uncertainties on $\Delta P_{\text {therm }}$ are only found on the magnitude of the change, because it is strongly associated with large-scale changes in global mean surface temperature.

Uncertainties in simulating changes in the dynamics contribute strongly to the uncertainty in simulating the evolution of future Sahel precipitation. We therefore decomposed $\Delta P_{d y n}$ into two subterms, $\Delta P_{\text {weak }}$ and $\Delta P_{\text {shift }}$ While $\Delta P_{\text {weak }}$ documents the change in the mean tropical circulation, $\Delta P_{\text {shift }}$ represents the change in precipitation that is induced by shifts in the circulation.

In a warmer climate the tropical mean circulation is expected to weaken (Held and Soden 2006), because moisture increases more strongly than precipitation, in percent of warming, over the tropics (constraining $\mathrm{M}^{*}$ to decrease in a warmer climate). $\Delta P_{\text {weak }}$ is then negative (Fig. 4c), implying that the weakening of the tropical circulation leads to a decrease in precipitation over the Sahel. The rationale is that the warming of the tropical mean SST is associated with a strong upper atmosphere warming and a change in the atmospheric vertical stratification, which is associated (a) $\Delta P_{\text {therm }}$ spread

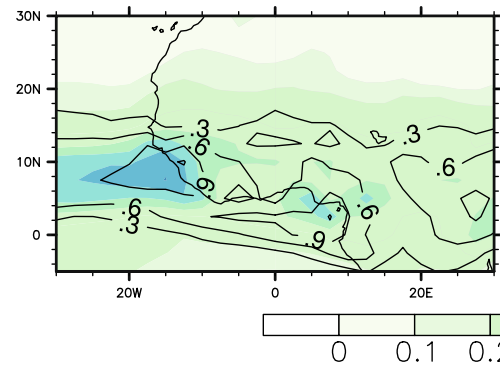

(b) $\Delta P_{\text {dyn }}$ spread

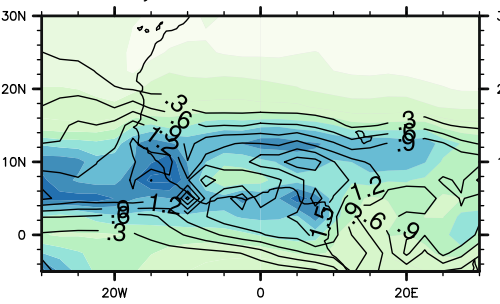

(c) $\Delta \mathrm{P}_{\text {cross }}$ spread
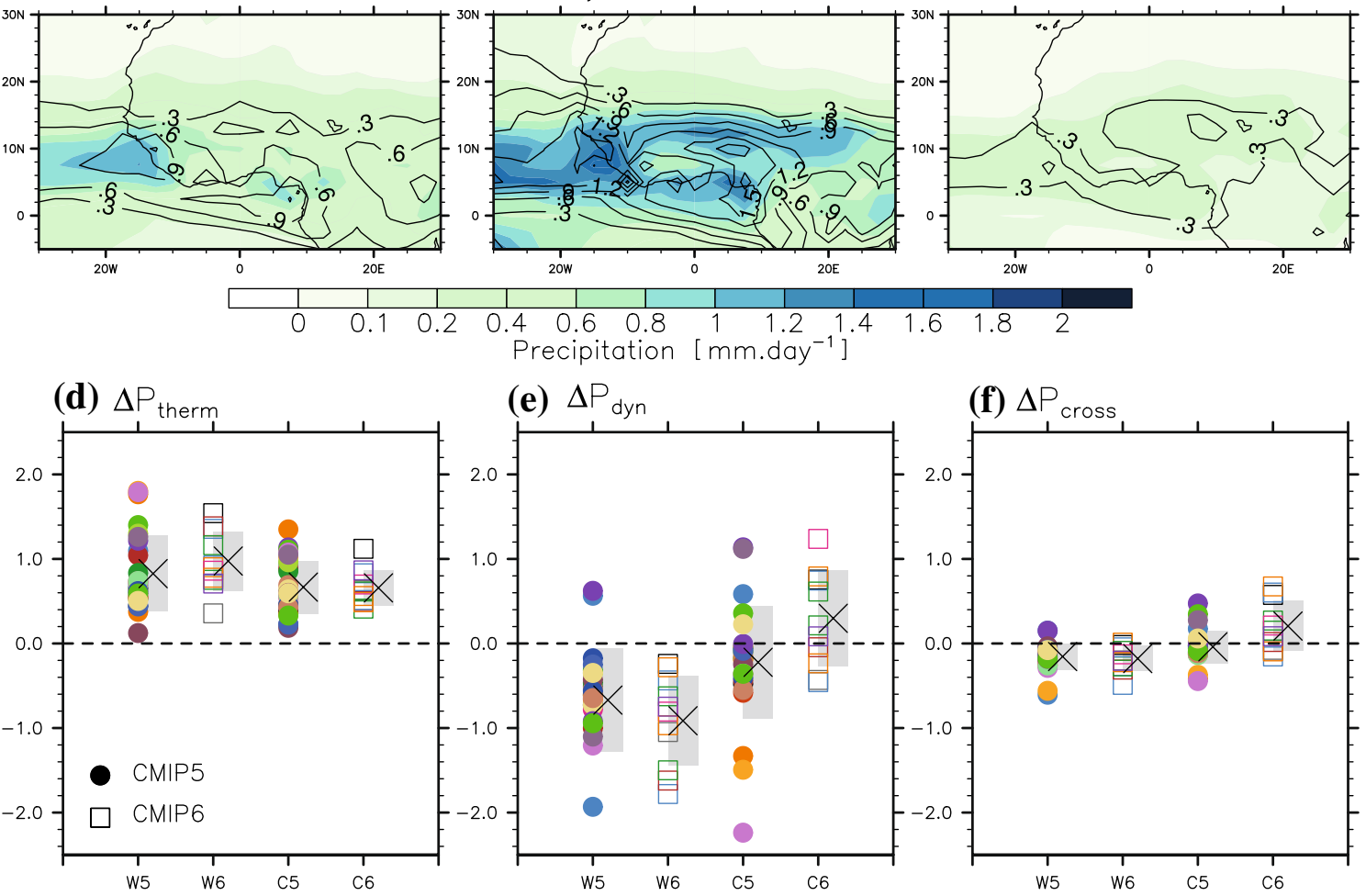

(e) $\Delta P_{\text {dyn }}$
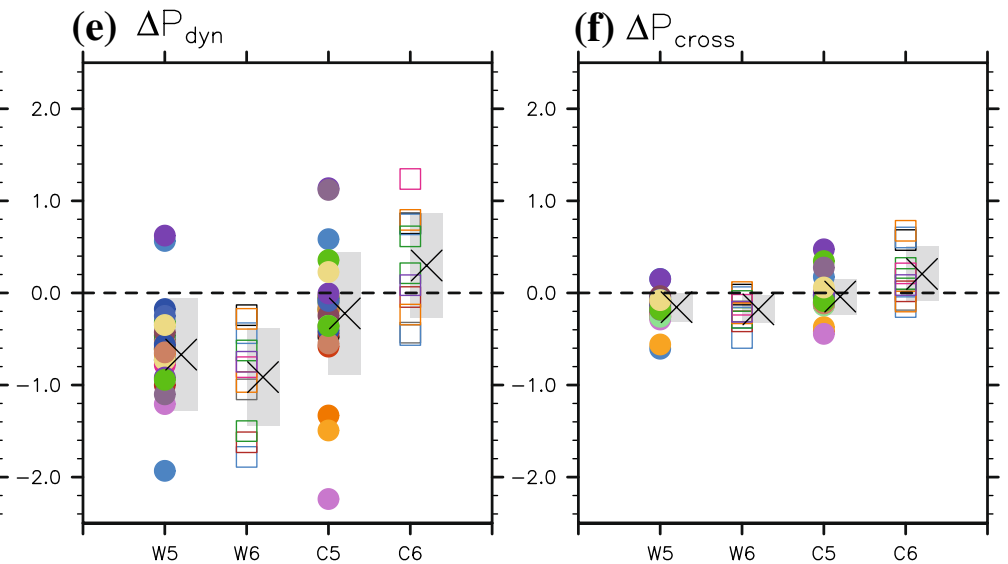

Fig. 3 Inter-model spread in a $\Delta \mathrm{P}_{\text {therm }}, \mathbf{b} \Delta \mathrm{P}_{\text {dyn }}$ and $\mathbf{c} \Delta \mathrm{P}_{\text {cross }}$ for the CMIP5 (colour) and the CMIP6 (black contours) ensemble. Changes in $\mathbf{d} \Delta \mathrm{P}_{\text {therm }}, \mathbf{e} \Delta \mathrm{P}_{d y n}$ and $\mathbf{f} \Delta \mathrm{P}_{\text {cross }}$ for each model (colours), the multimodel mean average (black cross) and the inter-model spread (from one standard deviation; grey shading). CMIP5 simulations ("5") are represented by a filled circle while CMIP6 simulations ("6") are represented by an empty square. $\mathbf{d}-\mathbf{f}$ Results are given for the western ("W") and the central ("C") Sahel. Please Fig. 2e for model's names 
Fig. 4 Inter-model spread in a $\Delta \mathrm{P}_{\text {weak }}$ and $\mathbf{b} \Delta \mathrm{P}_{\text {shift }}$ for the CMIP5 (colour) and the CMIP6 (black contours) ensemble. Changes in $\mathbf{c} \Delta \mathrm{P}_{\text {weak }}$ and $\mathbf{d}$ $\Delta \mathrm{P}_{\text {shift }}$ for each model (colours), the multi-model mean average (black cross) and the inter-model spread (from one standard deviation; grey shading). CMIP5 simulations (" 5 ") are represented by a filled circle while CMIP6 simulations (" 6 ") are represented by an empty square. $\mathbf{d}-\mathbf{f}$ Results are given for the western ("W") and the central ("C") Sahel. Please Fig. 2e for model's names (a) $\Delta P_{\text {weak }}$ spread
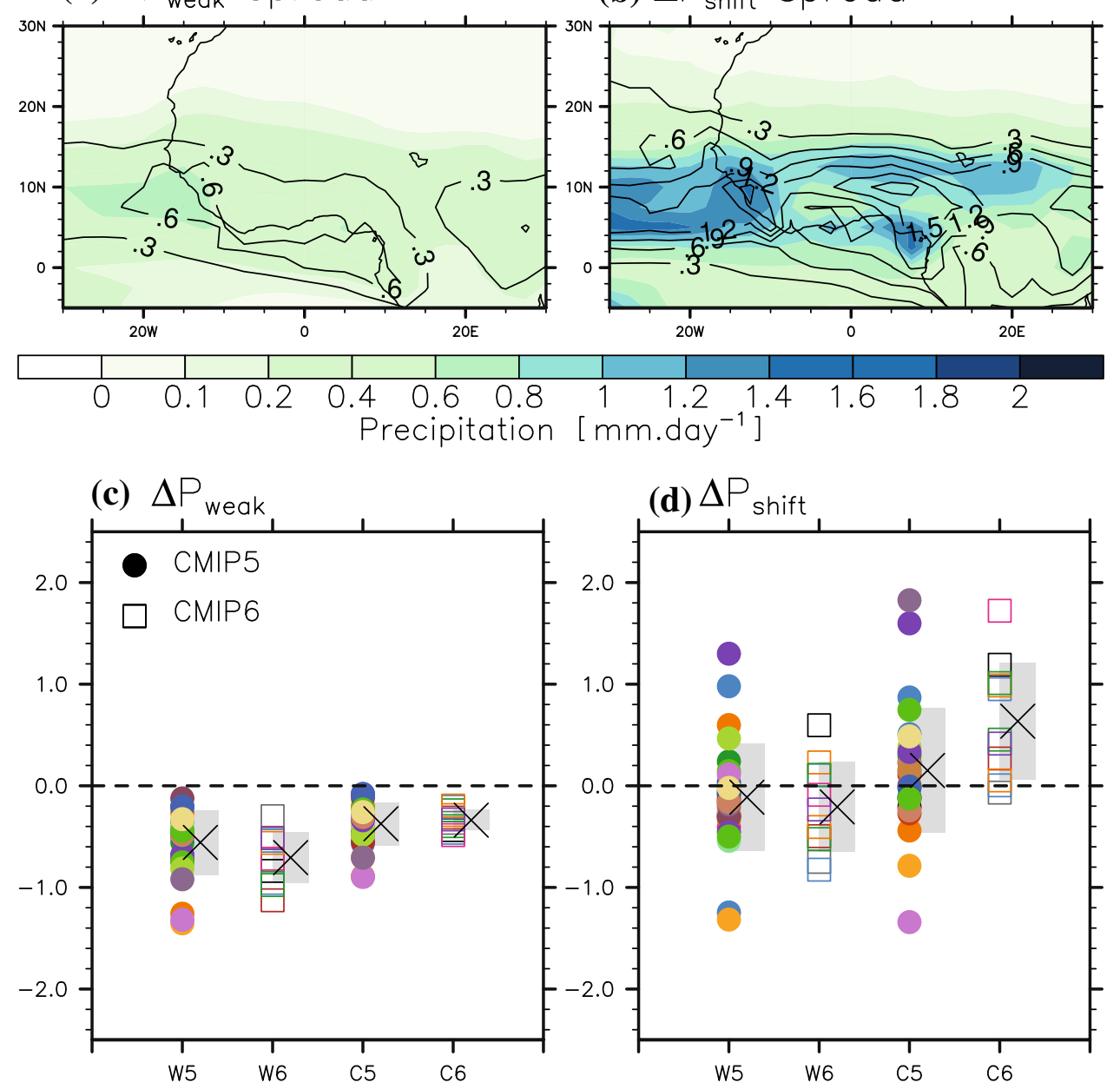

with a weakening of the Hadley circulation (Ma et al. 2011, 2018), for which the West African Monsoon is a facet (Biasutti et al. 2018). The shift in the circulation is leading, on average, to a moderate change in precipitation over the Sahel (Fig. 4d), and the magnitude of $\Delta P_{d y n}$ is mostly due to the weakening of the tropical circulation, rather than to a shift in the circulation. The inter-model spread in $\Delta P_{\text {shift }}$ is much stronger than in $\Delta P_{\text {weak }}$ in terms of magnitude and sign (Fig. 4a-d).

The thermodynamic term can be partitioned into a component due to increased maritime moisture advection onto land and a residual associated with changes in circulation, evaporation and vertical mixing (Chadwick et al. 2016; Rowell and Chadwick 2018), by decomposing the change in near-surface specific humidity. A fraction of the inter-model $\Delta P_{\text {therm }}$ spread could, therefore, be attributed to changes in the atmospheric circulation. The advection term (i.e. $\Delta P_{q a d v}$ ) is obtained, over land only, using $\Delta P_{\text {qadv }}=M^{*} \Delta q_{a d v}$, with $\Delta q_{a d v}=q_{\text {land_future }}-q_{\text {land }}$ ) (see Chadwick et al. 2016). $q_{\text {land_future }}$ is obtained by scaling $q_{\text {land }}$ (i.e. the historical mean specific humidity for each grid point over land) by the zonal mean fractional change in $q_{\text {ocean }}$ (i.e. the specific humidity over the ocean only) at the same latitude, with no change in the circulation

This implies that changes in maritime advection are mostly zonal over the Sahel. However, this has been shown to be true in Lélé et al. (2015). The residual is the change in precipitation associated with the change in specific humidity, but that is not due to $\Delta q_{a d v}$, over land and with no dynamic changes (i.e. $\Delta P_{\text {res }}=M^{*} \Delta q_{\text {res }}$; with $\Delta q_{\text {res }}=\Delta q-\Delta q_{a d v}$ ). $\Delta P_{q a d v}$ and $\Delta P_{\text {res }}$ inter-model spread is found to be moderate over both the central and the western Sahel and both CMIP5 and CMIP6 ensembles (Fig. S7).

An enhanced moisture advection from the oceans $\left(\Delta P_{q a d v}\right)$ increases precipitation over the Sahel, while the warming of the tropical SSTs is associated with a weakening of the tropical circulation $\left(\Delta P_{\text {weak }}\right)$ that reduces precipitation. Thus, there is a physical cancelation between $\Delta P_{\text {qadv }}$ and $\Delta P_{\text {weak }}$. We combined both terms and found that $\Delta P_{\text {qadv }}$ is slightly stronger than $\Delta P_{\text {weak }}$, leading to a moderate wetting of the Sahel (Fig. 5c), but its inter-model spread is moderate and does not mainly contribute to the $\Delta P$ inter-model spread 
Fig. 5 Inter-model spread in $\mathbf{a} \Delta \mathrm{P}_{\text {weak }}+\Delta \mathrm{P}_{\text {qadv }}$ and $\mathbf{b} \Delta \mathrm{P}_{\text {shift }}+\Delta \mathrm{P}_{\text {res }}$ for the CMIP5 (colour) and the CMIP6 (black contours) ensemble. Changes in $\mathbf{c} \Delta \mathrm{P}_{\text {weak }}+\Delta \mathrm{P}_{\text {qadv }}$ and $\mathbf{d}$ $\Delta \mathrm{P}_{\text {shift }}+\Delta \mathrm{P}_{\text {res }}$ for each model (colours), the multi-model mean average (black cross) and the inter-model spread (from one standard deviation; grey shading). CMIP5 simulations ("5") are represented by a filled circle while CMIP6 simulations ("6") are represented by an empty square. $\mathbf{d}-\mathbf{f}$ Results are given for the western ("W") and the central ("C") Sahel. Please Fig. 2e for model's names
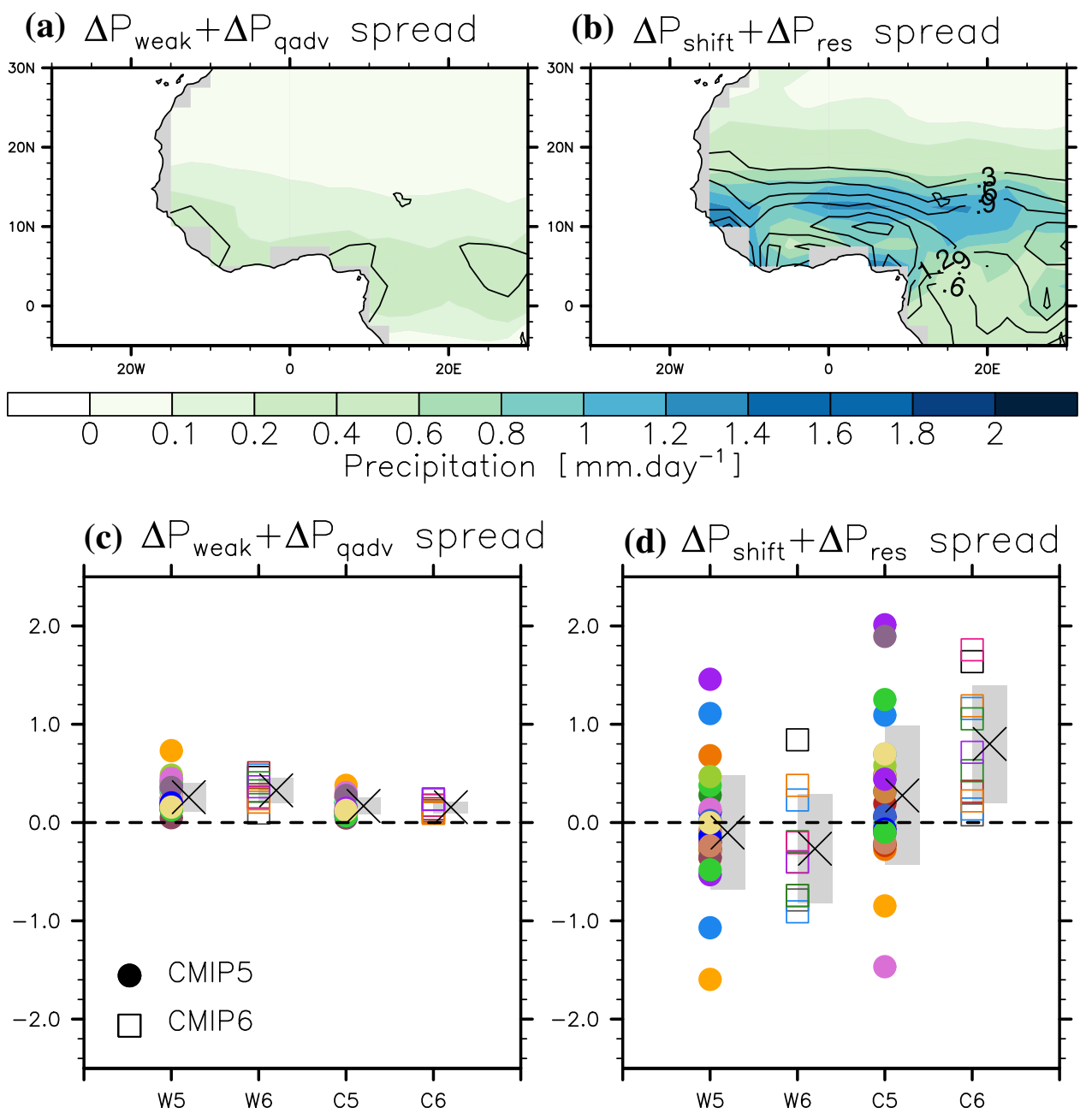

(Fig. 5a). Similarly, we combined $\Delta P_{\text {res }}$ and $\Delta P_{\text {shift }}$ that are associated with changes in the dynamic. As $\Delta P_{\text {res }}$ has a moderate magnitude, the $\Delta P_{\text {res }}+\Delta P_{\text {shift }}$ term is dominated by the shift in the circulation (Fig. $5 \mathrm{~d}$ ). The $\Delta P_{\text {res }}+\Delta P_{\text {shift }}$ inter-model spread is high, slightly higher than for $\Delta P_{\text {shift }}$ only (Fig. 5b).

The pattern of the inter-model precipitation change spread (Fig. 1a, b) is very similar to the pattern and magnitude of the spread in the change in the dynamic (Fig. 3b) and shift in the circulation (Figs. $4 \mathrm{~b}$ and $5 \mathrm{~b}$ ). Therefore, we suggest that changes in patterns of the circulation are thus the main contributor to the total uncertainties in Sahel precipitation change at the end of the 21 st century.

To assess how the inter-model spread is tied to one particular term, we computed precipitation change by replacing, successively, each term by its multi-model mean. For instance, we removed the model dependency to $\Delta P_{\text {therm }}$ by computing precipitation, for each model, as $\Delta P=\Delta P_{\text {therm }}+\Delta \mathrm{P}_{\text {shift }}+\Delta \mathrm{P}_{\text {cross }}+\Delta \mathrm{P}_{\text {cross }}$, where the overbar indicates the multi-model mean. The operation is repeated for all terms. Although results are giving the same values in the multi-model mean $\Delta P$, the inter-model spread is strongly impacted. Removing the inter-model uncertainties in $\Delta P_{\text {therm }}$ does not dramatically reduce the inter-model spread (Fig. 6a), which is comparable, in terms of pattern and magnitude, to the total inter-model spread (Fig. 1c, d). A similar conclusion is reached with $\Delta P_{\text {weak }}$ (Fig. 6b). However, the inter-model spread is strongly reduced when removing the dependency to the $\Delta P_{\text {shift }}$ spread, underlining that uncertainties in projecting precipitation are mostly due to the changes in the shift of the atmosphere circulation (Fig. 6c). $\Delta P_{\text {cross }}$ also slightly impacts the inter-model spread in $\Delta P$, but its role is moderate (Fig. $6 \mathrm{~d}$ ).

\subsection{Decomposing uncertainties due to thermodynamic and dynamic changes}

As $\Delta P_{d y n}$ is obtained by the product of the mean climatological specific humidity times the change in circulation (i.e. $\Delta P_{d y n}=q \Delta M^{*} ;$ Eq.2), uncertainties associated with $\Delta P_{d y n}$ could be due to either the ability of climate models to simulate the observed specific humidity or to a disagreement onto 
(a) $\Delta \mathrm{P}$ spread with $\Delta \mathrm{P}_{\text {therm }}$ mean

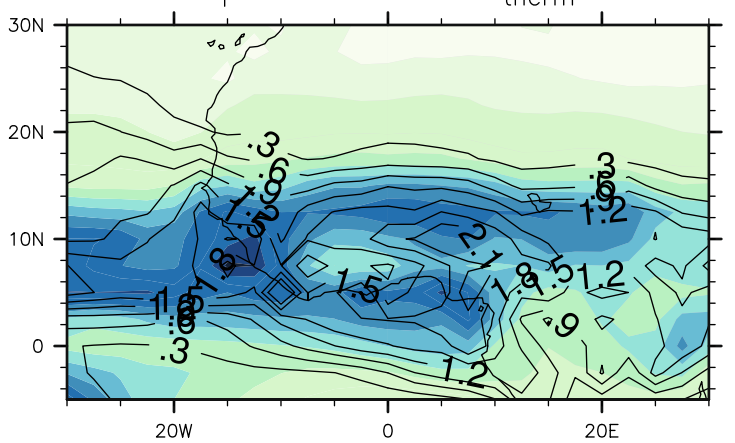

(d)

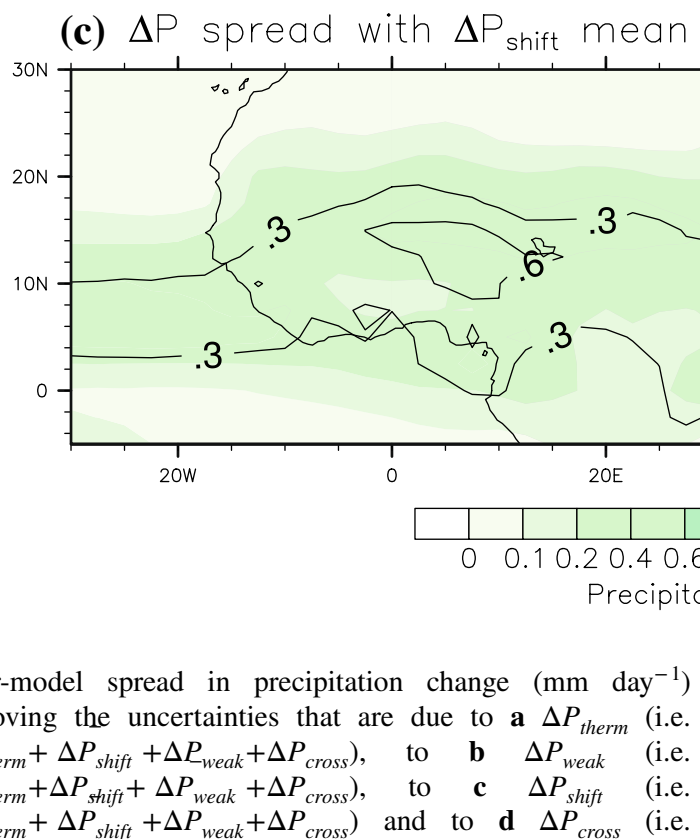

Fig. 6 Inter-model spread in precipitation change $\left(\mathrm{mm} \mathrm{day}{ }^{-1}\right)$ when removing the uncertainties that are due to a $\Delta P_{\text {therm }}$ (i.e. $\Delta P=\Delta P_{\text {therm }}+\Delta P_{\text {shift }}+\Delta P_{\text {weak }}+\Delta P_{\text {cross }}$ ), to b $\Delta P_{\text {weak }}$ (i.e. $\Delta P=\Delta P_{\text {therm }}+\Delta P_{\text {shift }}+\Delta P_{\text {weak }}+\Delta P_{\text {cross }}$ ), to c $\Delta P_{\text {shift }}$ (i.e. $\Delta P=\Delta P_{\text {therm }}+\Delta P_{\text {shift }}+\Delta P_{\text {weak }}+\Delta P_{\text {cross }}$ ) and to d $\Delta P_{\text {cross }}$ (i.e.

a common change in atmospheric dynamics. We then recomputed $\Delta P_{d y n}$ but using two different methods. In method 1 , we used the multi-model mean specific humidity $(q)$ to compute $\Delta P_{d y n}$, i.e. the inter-model spread is thus only due to the spread in projecting changes in circulation. This term is hereafter noted $\Delta P_{d d_{\_} m}$. In the second method, $\Delta P_{d y n}$ is computed for each model using the multi-model mean in circulation change, and the spread is thus only due to disagreements between the simulated historical specific humidity field. The term is hereafter noted $\Delta P_{d y_{-} q}$. Computing these terms highlights that the $\Delta P_{d y n}$ inter-model spread is due to how models simulate a change in the circulation rather than how they simulate historical specific humidity over the Sahel (Fig. 7a, b). Selecting models on their ability to simulate specific humidity might therefore not be useful to reduce uncertainties in a set of CMIP simulations.

The inter-model spread in $\Delta P_{\text {therm }}$ is due to both spread in $M^{*}$ and in $q$ (see Eq. 2). We then compute $\Delta P_{\text {therm }}$ using the multi-model mean average in $M^{*}$, allowing the intermodel spread to be only due to how models simulate the (b) $\Delta \mathrm{P}$ spread with $\Delta \mathrm{P}_{\text {weak }}$ mean

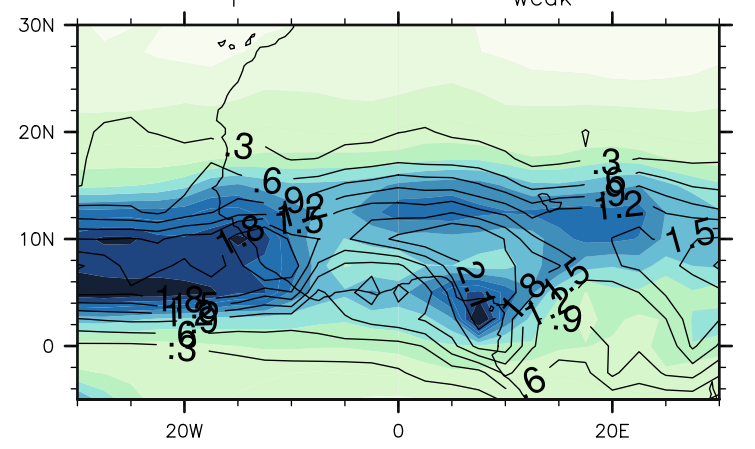

(d) $\Delta \mathrm{P}$ spread with $\Delta \mathrm{P}_{\text {cross }}$ mean

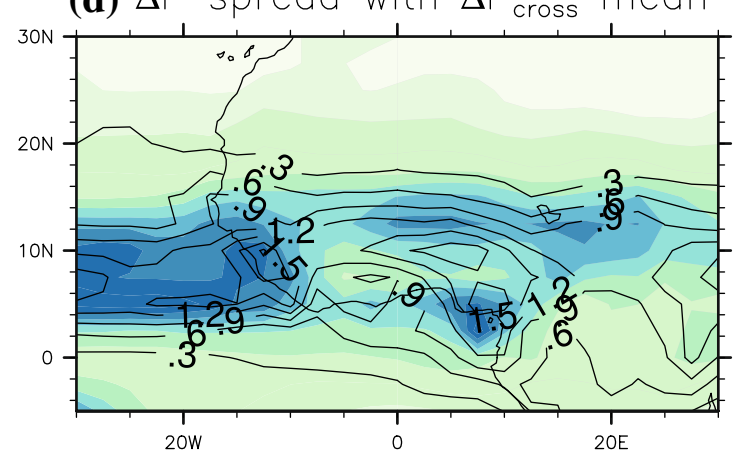

$8 \begin{array}{lllllll} & 1 & 1.2 & 1.4 & 1.6 & 1.8 & 2\end{array}$

$\left[\mathrm{mm} \cdot \mathrm{day}^{-1}\right]$

$\left.\Delta P=\Delta P_{\text {therm }}+\Delta P_{\text {shift }}+\Delta P_{\text {weak }}+\Delta P_{\text {cross }}^{-}\right) . \Delta P$ is computed for each model and the overbar indicates the multi-model mean. Results are given in colour for the CMIP5 ensemble and in contours for the CMIP6 ensemble

change in specific humidity (this term is hereafter noted $\Delta P_{\text {th }} q$ ), and using the multi-model mean average in $\Delta q$, allowing the inter-model spread to be then only due to divergences between model's simulations of historical circulation (this term is hereafter noted $\Delta P_{t h \_m}$ ). The intermodel spread is then of similar importance between $\Delta P_{t h \_} q$ and $\Delta P_{t h \_m}$ showing that both uncertainties in the change in specific humidity and in how models simulate the historical circulation contribute to the total spread of the thermodynamic component (Fig. 7a, b). The same conclusions are drawn for the CMIP6 and the CMIP5 simulations.

The focus is now made on $\Delta P_{d y \_}$, which mainly contributes to uncertainties in Sahel precipitation change. The maps of the correlation between the area-averaged western and central Sahel $\Delta P_{d y \_}$and changes in surface-air temperature show where there is a relationship between changes in temperature and changes in $\Delta P_{d y_{-} m}$ (Fig. 7c, d). Changes in global mean surface temperature are strongly related to the climate model's sensitivity to the external forcing and local temperature is therefore scaled by each 

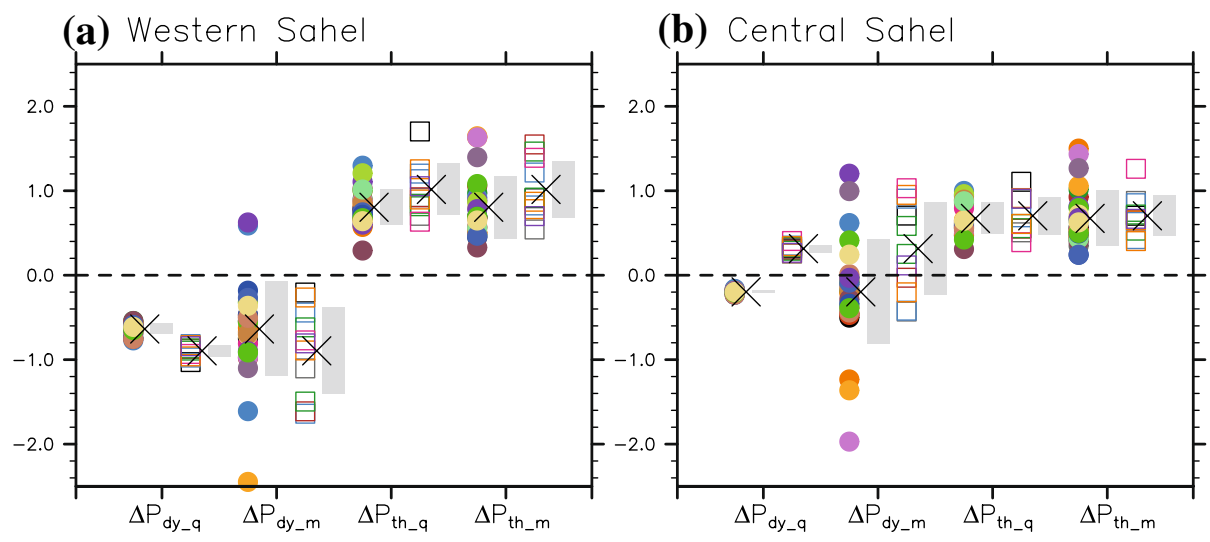

(c) Western Sahel CMIP5

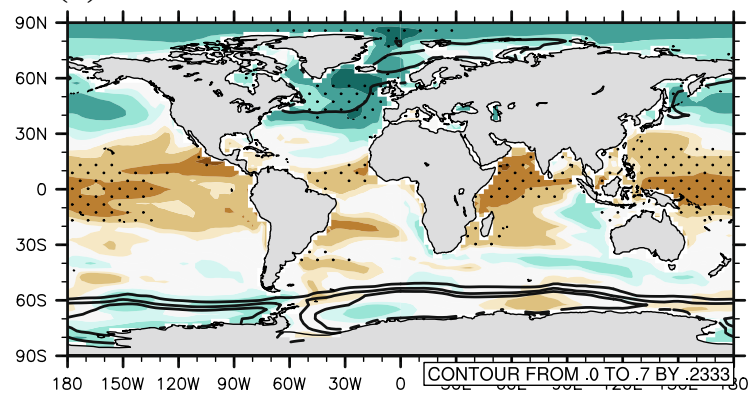

(d) Central Sahel CMIP5
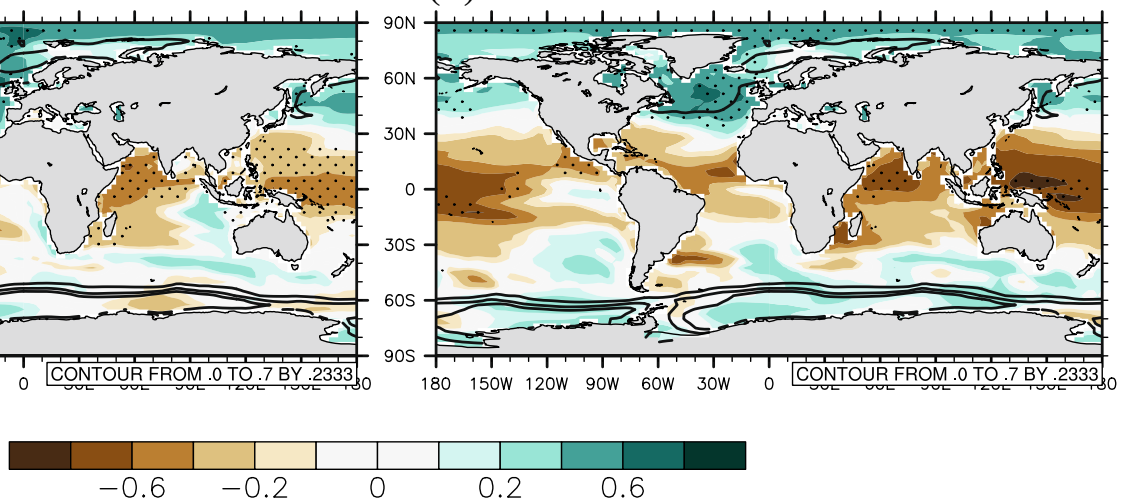

(e) Western Sahel CMIP6

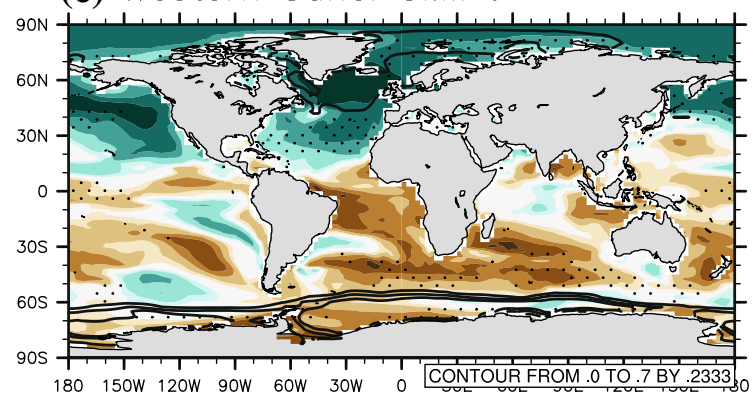

(f) Central Sahel CMIP6
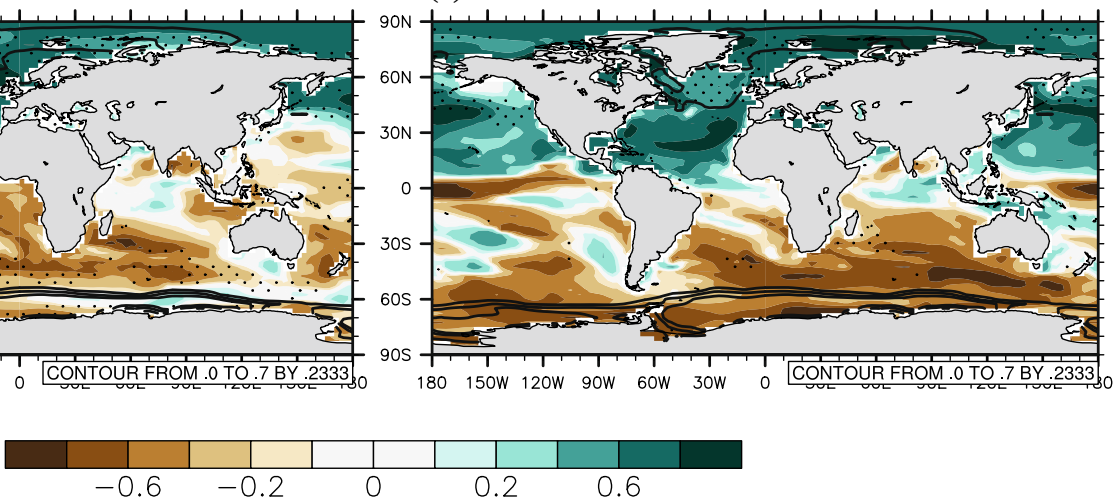

Fig. 7 Contribution of $\mathrm{q}\left(\Delta \mathrm{P}_{d y_{-} q}\right)$ and $\Delta\left(\mathrm{M}^{*}\right)\left(\Delta \mathrm{P}_{d y_{-} m}\right)$ to $\Delta \mathrm{P}_{d y n}$ and to $\Delta(\mathrm{q})\left(\Delta \mathrm{P}_{\text {th } \_q}\right)$ and $\mathrm{M}^{*}\left(\Delta \mathrm{P}_{\text {th } \_m}\right)$ to $\Delta \mathrm{P}_{\text {therm }}$ for the $\mathbf{a}$ West and $\mathbf{b}$ central Sahel. Results are given for each model, for the multi-model mean average (black cross) and the inter-model spread (grey shading). CMIP5 simulations are represented by a filled circle while CMIP6 simulations are represented by an empty square. Maps of the correlation between the change in averaged $\mathbf{c}$ West and $\mathbf{d}$ central $\Delta \mathrm{P}_{d y_{-} m}$

model's change in global mean surface air temperature prior to computing the correlations.

Uncertainties in the dynamic are associated with changes in surface-air temperature over the tropics and over the North Atlantic Ocean (Fig. 7c, d). It has been shown that a warming of the North Atlantic Ocean is associated with a northward shift of the Intertropical Convergence Zone term and local change in surface-air temperature (both scaled by each model's change in global mean surface air temperature) for the CMIP5 ensemble. e and $\mathbf{f}$ same as $\mathbf{c}$ and $\mathbf{d}$ but for the CMIP6 ensemble. The spread in temperature changes is plotted with the black contour and stippling indicates that the correlation is significant, according to a Student's $t$ test at a 95\% confidence level

over the tropical Atlantic Ocean and northern Africa (See for instance, Martin and Thorncroft 2014; Monerie et al. 2019). The positive correlation shows that the more the North Atlantic warms, the more precipitation increases over the Sahel. In addition, the inter-model spread in projected surface-air temperature over the North Atlantic Ocean is high (see the contours on the Fig. 7c, d). The CMIP6 
simulations also highlight the importance of the Atlantic Ocean in explaining discrepancies between climate models (Fig. 7e, f). However, for the western Sahel precipitation, the models' discrepancies are related to the tropical North Atlantic rather than to the extratropical Atlantic (Fig. 7e) and the change in the mean tropical surface-air temperature over the ocean is not clear.

A negative correlation is obtained with the surface-air temperature over the tropics, showing that precipitation increases over the Sahel when the tropics are anomalously cold, in the set of CMIP5 models (Fig. 7c, d). This is consistent with the fact that a warming of the tropics leads to a decrease in precipitation over the Sahel (Gaetani et al. 2017). However, the inter-model spread in simulating changes in surface air temperature over the tropics is relatively low.

The negative correlation obtained over the tropics and the positive correlation obtained over the extratropics form the northern Hemisphere differential warming that is suggested to be one of the main sources of uncertainty in Sahel precipitation change (Park et al. 2015). For the CMIP6 models, an inter-hemispheric gradient strongly appears to be the cause of model's uncertainties in simulating future precipitation change over the Sahel. Different oceanic responses could therefore be at play between the CMIP5 and the CMIP6 simulations. However, differences could also be due to the relatively small CMIP6 ensemble size, and would have to be confirmed with a larger set of simulations, which will be the scope of further studies. Although the increase in temperature is higher in the CMIP6 than in the CMIP5 ensemble member (Fig. S4), large-scale changes in temperature are similar between both generation of CMIP models and differences between Fig. 7c, d and Fig. 7e, f do not reflect major changes in responses of surface-air temperature to the forced response (Fig. S4). It is worth noting that the same response is obtained when replacing $\Delta P_{d y_{-} m}$ by $\Delta P_{\text {shift }}$ or by $\Delta P_{\text {shift }}+\Delta P_{\text {res }}$, with a high pattern correlation between obtained correlation maps.

\subsection{Magnitude of the warming, and role of the oceanic basins}

Caution is needed when interpreting correlations across features of multi-model ensembles, because climate models are not really independent (Masson and Knutti 2011; Boé 2018), and, because correlation does not prove causality. The role of the sea surface temperature on Sahel precipitation is further assessed.

Uncertainty in simulating precipitation change could be due to differences in the model's climate sensitivity. To assess this issue, we have used two different approaches, following Kent et al. (2015). First, we have scaled the changes in precipitation by the global mean surface-air temperature change, for each model and at each grid point. Then we have computed the inter-model spread in scaled precipitation change. Second, the operation is repeated but by scaling changes in precipitation by the multi-model change in global mean surface-air temperature. In the former approach, we remove the dependence of the inter-model uncertainty on global mean temperature changes while in the latter we do not. The inter-model spread is computed in both cases and the difference between the first and the second approach (i.e. the first approach minus the second approach) is displayed in Fig. 8, in percentage. By scaling the change in precipitation by the change in global mean surface temperature we assume that precipitation increases linearly to the change in temperature. This has shown to be true on the global scale (Neelin et al. 2006).

Differences are less than $10 \%$ over most of the Sahel, showing that uncertainties are not mainly due to the model's uncertainty in climate sensitivity to imposed radiative forcing following an increase in atmospheric greenhouse gas concentration (Fig. 8). This is consistent with Kent et al. (2015), who reached the same conclusion on a global scale.

We note a link between changes in temperature over the tropics, the North Atlantic and Sahel precipitation. We have therefore explored the importance of different oceanic basins on the inter-model spread in Sahel precipitation change. As changes in temperature are not only local but exhibit global patterns, we consider changes in temperature by using temperature gradients. We assess changes due to the difference in temperature between the North Atlantic and the tropical Atlantic Ocean, between the extratropical Northern Hemisphere and the tropics (as in Park et al. 2015), and for the inter-hemispheric temperature gradient.

(a) Global mean surface air temperature

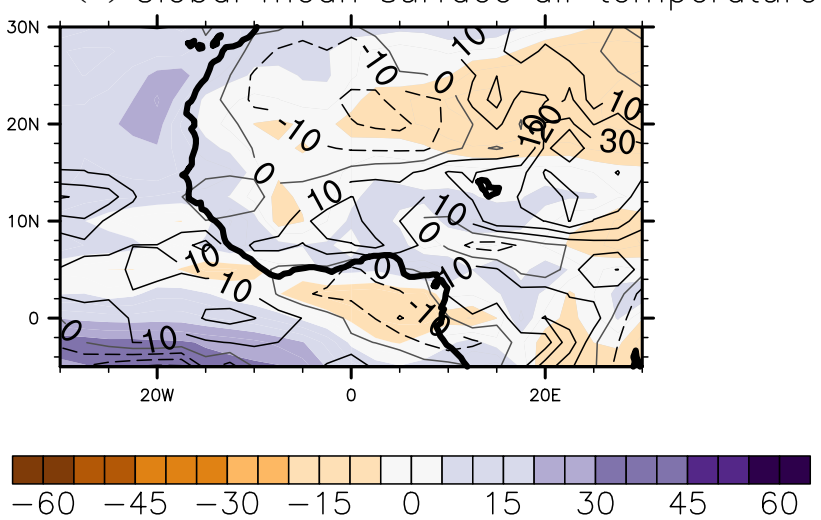

Fig. 8 a Percentage changes (\%) between the inter-model precipitation change standard deviation after normalisation by each model's global surface temperature change and the inter-model precipitation change standard deviation after normalization by the multi-model mean global surface temperature change. Results are given in colour for the CMIP5 ensemble and with contours for the CMIP6 ensemble (every $10 \%)$ 
First, we confirm that a large inter-model spread is obtained when simulating future changes in temperature over the oceans (Fig. 9a), with a stronger strengthening of the oceanic temperature gradients for the CMIP6 than for the CMIP5 multi-model mean. Second, we assess the relationship between the different oceanic basins and Sahel precipitation by regressing the oceanic indices onto the western and central Sahel precipitation, using the CMIP5 and CMIP6 pre-industrial control runs (Fig. 9b, c). We used pre-industrial control simulations to assess impacts

(a) $\Delta$ tas

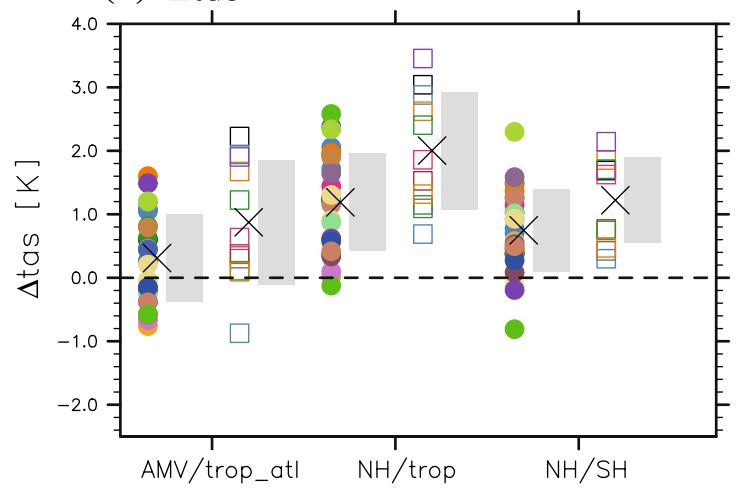

(b) reg_west

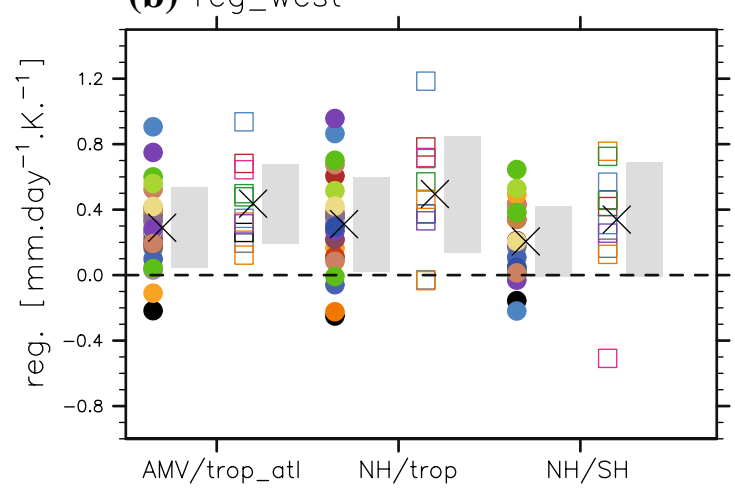

(d) $\Delta \mathrm{P}^{\prime}$ _west

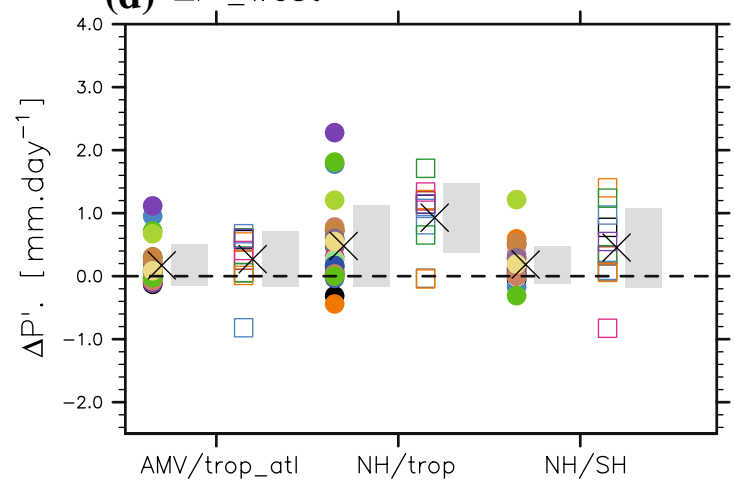

Fig. 9 a Changes in the North Atlantic $\left[60^{\circ} \mathrm{W}-0^{\circ} \mathrm{W} ; 20^{\circ} \mathrm{N}-60^{\circ} \mathrm{N}\right] /$ tropical Atlantic Ocean $\left[60^{\circ} \mathrm{W}-0^{\circ} \mathrm{W} ; 20^{\circ} \mathrm{S}-20^{\circ} \mathrm{N}\right]$ temperature gradient (i.e. AMV/trop_atl), in the extratropical northern Hemisphere $\left[20^{\circ} \mathrm{N}-75^{\circ} \mathrm{N} ; 0-360^{\circ} \mathrm{E}\right] /$ tropical temperature $\left[20^{\circ} \mathrm{S}-20^{\circ} \mathrm{N} ; 0-360^{\circ}\right.$ E] (i.e. $\mathrm{NH} /$ trop) and in the North Hemisphere $\left[0-90^{\circ} \mathrm{N} ; 0-360^{\circ} \mathrm{E}\right] /$ South Hemisphere $\left[90^{\circ} \mathrm{S}-0^{\circ} ; 0-360^{\circ} \mathrm{E}\right]$ temperature gradient due to climate change in JAS (in $\mathrm{K}$ ). Impact of climate change is obtained as the difference between the 2060-2099 period (under the RCP8.5 emission scenario for the CMIP5 ensemble and the SSP585 emission scenario for the CMIP6 ensemble) and the 1960-1999 historical

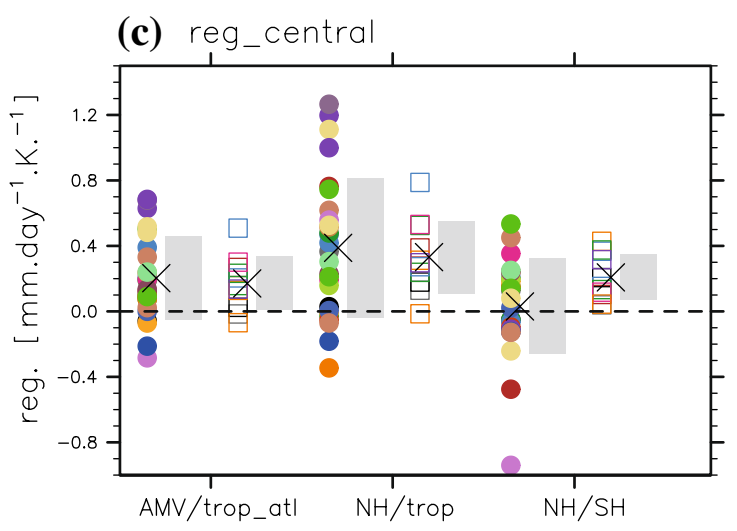

(e) $\Delta \mathrm{P}^{\prime}$ _central

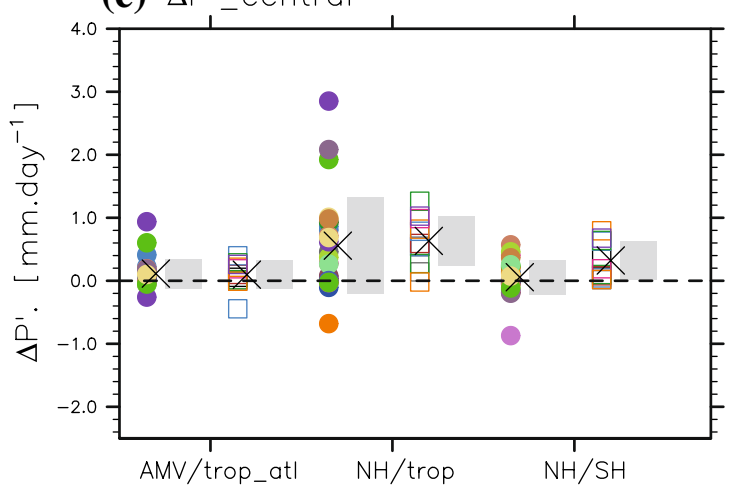

period. Regression between the oceanic temperature gradients and $\mathbf{b}$ western and $\mathbf{c}$ central Sahel precipitation (in $\mathrm{mm} \mathrm{day}^{-1} \mathrm{~K}^{-1}$ ), as computed in JAS using the pre-industrial control simulations. Impact of each oceanic temperature gradients on $\mathbf{d}$ western and e central Sahel precipitation (in $\mathrm{mm} \mathrm{day}^{-1}$ ) as computed as the product of the change in temperature gradients (a) times the impact of each oceanic temperature gradient on Sahel precipitation $(\mathbf{b}, \mathbf{c})$ (see the text). MRI-ESM1 and GFDL-ESM2G (two CMIP5 models) have been discarded due to a lack of available Pre-industrial control data at the time of the study. Please Fig. 2e for model's names 
of SST internal climate variability on Sahel precipitation, removing the influence of GHGs. Then, we use the assumption that SSTs-Sahel precipitation teleconnections are not modulated by the forced response. This is an approximation that would be assessed using large-ensembles, as done in (Fasullo et al. 2018) for instance.

On average, the Atlantic Ocean gradient is associated with an increase in precipitation over both the central and the western Sahel. However, several models produce lower Sahel precipitation when the North Atlantic Ocean is anomalously warm. The northern hemisphere differential warming and the increase of the inter-hemispheric temperature gradient are associated with an increase in precipitation over the Sahel and exhibit a strong inter-model spread (Fig. 9b, c).

We assess the impact of the change in the oceanic temperature on Sahel precipitation. We compute the impacts of the oceanic basins as $\Delta P^{\prime}=\propto \Delta T$, where $\Delta P^{\prime}$ is the change in precipitation that is associated with each oceanic basin (in mm day ${ }^{-1}$ ), $\Delta T$ is the change in temperature that is due to climate change, over each oceanic basin (in K; i.e. Fig. 9a), and $\propto$ the regression between each oceanic basin and Sahel precipitation. $\propto$ is computed from the pre-industrial control simulations (in mm day ${ }^{-1} \mathrm{~K}^{-1}$; Fig. 9b, c).

Results are given in Fig. 9d and e. In the CMIP5 ensemble, the northern-hemisphere differential warming has a stronger impact than the inter-hemispheric gradients and the Atlantic gradient on the $\Delta P^{\prime}$ inter-model spread. However, both inter-hemispheric and northern-hemispheric gradients are of similar importance within the CMIP6 ensemble.

We confirm a large role of the Northern Hemisphere differential warming on the precipitation change uncertainty by computing the correlation between the change in the Northern Hemisphere differential warming and the change in Sahel precipitation across the CMIP5 ensemble. We find correlations of $r=0.52$ for the western Sahel precipitation and $r=0.73$ for the central Sahel precipitation (all significant at the 95\% confidence level with a Student's $t$ test). Within the CMIP5 ensemble, stronger correlations are found between $\Delta P^{\prime}$ (associated with northern Hemisphere differential warming) and $\Delta P$, with $\mathrm{r}=0.71$ when considering western Sahel precipitation and $\mathrm{r}=0.84$ when considering central Sahel precipitation, showing that, in addition to the uncertainty in simulating changes in temperature over the ocean, uncertainties in simulating SSTs-Sahel precipitation teleconnections have also to be assessed. Within the CMIP6 ensemble the correlation between $\Delta P^{\prime}$ and $\Delta P$ is weaker $(\mathrm{r}=0.49$ for the western Sahel and $\mathrm{r}=0.59$ for the central Sahel) and the correlation between the change in the Northern Hemisphere differential warming and $\Delta P$ is still high $(\mathrm{r}=0.77$ for the western Sahel and $r=0.72$ over the central Sahel). However, the
CMIP6 ensemble size is relatively small in our analysis and such a relationship will be the topic of a further study.

\section{Discussion and conclusion}

We analysed the causes of the uncertainties in simulating future changes in precipitation over the Sahel, using a set of 29 CMIP5 simulations and of 11 CMIP6 simulations. Changes in precipitation patterns are strongly modeldependent (Monerie et al. 2016) and are associated with different mechanisms, which we assessed by decomposing precipitation change into dynamic, thermodynamic and cross (i.e. a change in both dynamic and thermodynamic) terms, following Chadwick et al. (2013, 2016).

Multi-model analysis shows that precipitation is projected to increase over the central Sahel and to decrease over the western Sahel. However, changes in precipitation are moderate in comparison to the inter-model spread in precipitation change (Fig. 1). Thus, precipitation change is uncertain over the Sahel. Decomposing precipitation helps to unravel causes of precipitation change discrepancies. Our main finding is that the inter-model spread in precipitation change is mostly associated with model uncertainties in projecting changes in atmospheric circulation. Moreover, the models' discrepancies are due to how models simulate changes in atmospheric circulation patterns rather than in the strength of the atmospheric circulation. This is consistent with Xie et al. (2015), who found a similar behaviour but focusing on the global pattern in precipitation change, rather than regional changes. Similarly to Kent et al. (2015), we found that uncertainties in projecting precipitation are not strongly influenced by uncertainty in global mean surface-air temperature change at the end of the 21 st century.

Although not physical, replacing the component of the precipitation that is associated with a shift in the atmospheric circulation by its multi-model mean helps to reduce strongly the spread in precipitation, without changing the magnitude of the multimodel mean change in precipitation (for each model: $\Delta P=\Delta P_{\text {therm }}+\Delta t P_{\text {weak }}+\Delta P_{\text {cross }}+$ multimodelmean $\left.\Delta P_{\text {shift }}\right)$. We do not suggest to remove this component to improve Sahel precipitation change, instead, we confirm that understanding better future shifts in circulation are mandatory to increase our confidence in Sahel precipitation projections.

An additional source of uncertainty is due to how models simulate thermodynamic changes over the Sahel. However, in all models, thermodynamic changes are leading to an increase in precipitation over the Sahel and the uncertainties are only found on the magnitude of the change.

Uncertainties are also expected to be associated with the ability of models to simulate the African climate over 
the historical period. We might have low confidence in models that have large biases in simulating the West African monsoon. We show, for instance, that model uncertainty in simulated historical pattern of atmospheric circulation is of importance (Fig. 7a, b). However, (Monerie et al. 2016; Yan et al. 2018) have also shown that there are no clear links between the abilities of climate models to simulate the historical Sahel precipitation and projections in Sahel precipitation.

We show a link between the future warming of the North Atlantic Ocean and the future change in Sahel precipitation. Models that simulate an anomalously warm (cold) North Atlantic Ocean also simulate an anomalously wet (dry) Sahel, relatively to the multi-model mean. However, as in Park et al. (2015), we state that uncertainties are mainly due to how models simulate the relationship between the large-scale Northern Hemisphere temperature gradient, and to how this temperature gradient changes due to climate change. We did not find a strong role of the tropical North-Atlantic/tropical South Atlantic temperature gradient on precipitation change uncertainty (not shown), which however has been linked to strong changes in Sahel precipitation (Hoerling et al. 2006). Uncertainties arise from either difference in the warming of the SSTs and the different responses of climate models to the same temperature anomaly (Gaetani et al. 2017). Indeed, we have shown that uncertainties concern both changes in oceanic temperature gradients and their impacts over land. A better understanding of both Sahel precipitation-SSTs teleconnections and temperature changes over the ocean is therefore mandatory to reduce discrepancies among climate models to better inform Sahelian societies.

Monerie et al. (2016) have shown that changes in northern Saharan surface-air temperature are model dependent. In this study, we have regressed changes in Sahel precipitation with changes in surface air temperature over land and did not find strong evidence to involve the Saharan warming to explain uncertainties over the Sahel (Fig. S8). Instead, the analysis is focused on the sources of uncertainties arising from changes in SST pattern and magnitude. Biasutti (2019) stated that uncertainties are stronger regarding changes in SST gradients than changes in the Saharan Heat Low since the latter includes uncertain outcomes in the oceanic dynamic responses. Therefore, we assume that further work should be devoted to understanding better the establishment of the Northern Hemisphere temperature gradient, and its impact on Sahel precipitation variability. We speculate that uncertainties in simulating this large-scale gradients could arise from discrepancies between climate models to simulate atmospheric energy balance that has been linked to variations of the ITCZ (Schneider et al. 2014a) and could be associated with errors in simulations of the cloud cover (Hwang and Frierson 2013) or could be associated with changes in Artic sea-ice (Deser et al. 2014; Monerie et al. 2018).
By mainly focusing on the role of the SSTs in shaping uncertainties in Sahel precipitation change we evade the influence of the Saharan heat low on Sahel precipitation change (Biasutti et al. 2009). The warming of the Saharan desert is associated with a shift in the location of the Saharan heat low that allows converging low-level moisture fluxes over the Sahel (Shekhar and Boos 2017). To go further, the respective roles of uncertainties on strength and location of the heat low and the changes in the SST gradients should then be assessed following the "storyline" approach of Zappa and Shepherd (2017), as proposed in Biasutti (2019), through assessing uncertainties associated with several drivers of the West African monsoon.

Acknowledgements Caroline M Wainwright's contribution has been supported by the NERC/DFID HyCristal project (NE/M020371/1). She is also grateful to the Mars Wrigley Confectionery research team for stimulating discussions on the wider context and applications of this work. Authors thank Dr. Robin Chadwick for his insightful and constructive comments on the precipitation decomposition. We acknowledge the World Climate Research Programme's Working Group on Coupled Modelling, which is responsible for CMIP, and we thank the climate modelling groups for producing and making available their model output. For CMIP the U.S. Department of Energy's Program for Climate Model Diagnosis and Intercomparison provides coordinating support and led development of software infrastructure in partnership with the Global Organization for Earth System Science Portals. GPCC and GPCP Precipitation data are provided by the NOAA/OAR/ESRL PSL, Boulder, Colorado, USA, from their Web site at https://psl.noaa. gov/.

Open Access This article is licensed under a Creative Commons Attribution 4.0 International License, which permits use, sharing, adaptation, distribution and reproduction in any medium or format, as long as you give appropriate credit to the original author(s) and the source, provide a link to the Creative Commons licence, and indicate if changes were made. The images or other third party material in this article are included in the article's Creative Commons licence, unless indicated otherwise in a credit line to the material. If material is not included in the article's Creative Commons licence and your intended use is not permitted by statutory regulation or exceeds the permitted use, you will need to obtain permission directly from the copyright holder. To view a copy of this licence, visit http://creativecommons.org/licenses/by/4.0/.

\section{References}

Adler RF, Huffman GJ, Chang A, et al (2003) The Version-2 Global Precipitation Climatology Project (GPCP) Monthly Precipitation Analysis (1979-Present). J Hydrometeorol 4:1147-1167. doi: https://doi.org/10.1175/1525-7541(2003)004<1147:TVGPCP> 2.0.CO;2

Aich V, Liersch S, Vetter T et al (2016) Flood projections within the Niger River Basin under future land use and climate change. Sci Total Environ 562:666-677. doi:https://doi.org/10.1016/j.scito tenv.2016.04.021

Akinsanola AA, Zhou W (2018) Ensemble-based CMIP5 simulations of West African summer monsoon rainfall: current climate and future changes. Theor Appl Climatol. doi:https://doi.org/10.1007/ s00704-018-2516-3 
Akinsanola AA, Zhou W (2019a) Projections of West African summer monsoon rainfall extremes from two CORDEX models. Clim Dyn 52:2017-2028. doi:https://doi.org/10.1007/s00382-018-4238-8

Akinsanola AA, Zhou W (2019b) Dynamic and thermodynamic factors controlling increasing summer monsoon rainfall over the West African Sahel. Clim Dyn 52:4501-4514. doi:https://doi. org/10.1007/s00382-018-4394-x

Akinsanola AA, Zhou W (2019c) Projection of West African summer monsoon rainfall in dynamically downscaled CMIP5 models. Clim Dyn 53:81-95. doi:https://doi.org/10.1007/s0038 2-018-4568-6

Angelina A, Djibo AG, Seidou O et al (2015) Changes to flow regime on the Niger River at Koulikoro under a changing climate. Hydrol Sci J 60:1709-1723. doi:https://doi.org/10.1080/02626 667.2014.916407

Barros VR, Field CB, Dokke DJ et al (2014) Climate change 2014: impacts, adaptation, and vulnerability-Part B: regional aspectsContribution of Working Group II to the Fifth Assessment Report of the Intergovernmental Panel on Climate Change

Biasutti M (2013) Forced Sahel rainfall trends in the CMIP5 archive. J Geophys Res Atmos 118:1613-1623. doi:https://doi.org/10.1002/ jgrd.50206

Biasutti M (2019) Rainfall trends in the African Sahel: characteristics, processes, and causes. Wiley Interdiscip Rev Clim Chang 10:e591. https://doi.org/10.1002/wcc.591

Biasutti M, Sobel AH, Camargo SJ (2009) The role of the Sahara low in summertime Sahel rainfall variability and change in the CMIP3 models. J Clim 22:5755-5771. https://doi.org/10.1175/2009J CLI2969.1

Biasutti M, Voigt A, Boos WR et al (2018) Global energetics and local physics as drivers of past, present and future monsoons. Nat Geosci 11:392-400. doi:https://doi.org/10.1038/s41561-018-0137-1

Boé J (2018) Interdependency in multimodel climate projections: component replication and result similarity. Geophys Res Lett 45:2771-2779. doi:https://doi.org/10.1002/2017GL076829

Chadwick R, Boutle I, Martin G (2013) Spatial patterns of precipitation change in CMIP5: why the rich do not get richer in the tropics. J Clim 26:3803-3822. doi:https://doi.org/10.1175/JCLID-12-00543.1

Chadwick R, Good P, Willett K (2016) A simple moisture advection model of specific humidity change over land in response to SST warming. J Clim 29:7613-7632. doi:https://doi.org/10.1175/ JCLI-D-16-0241.1

Cook KH, Vizy EK (2006) Coupled model simulations of the West African Monsoon system: twentieth- and twenty-first-century simulations. J Clim 19:3681-3703. doi:https://doi.org/10.1175/ JCLI3814.1

Deser C, Tomas RA, Sun L (2014) The role of ocean-atmosphere coupling in the zonal-mean atmospheric response to Arctic Sea ice loss. J Clim 28:2168-2186. doi:https://doi.org/10.1175/JCLID-14-00325.1

Druyan LM (2011) Studies of 21st-century precipitation trends over West Africa. Int J Climatol 31:1415-1424. doi:https://doi. org/10.1002/joc. 2180

Dunning CM, Black ECL, Allan RP (2016) The onset and cessation of seasonal rainfall over Africa. J Geophys Res Atmos 121:11,405411,424. doi:https://doi.org/10.1002/2016JD025428 doi

Dunning CM, Black E, Allan RP (2018) Later wet seasons with more intense rainfall over Africa under future climate change. J Clim 31:9719-9738. doi:https://doi.org/10.1175/JCLI-D-18-0102.1

Eyring V, Bony S, Meehl GA et al (2016) Overview of the coupled model intercomparison Project Phase 6 (CMIP6) experimental design and organization. Geosci Model Dev 9:1937-1958. doi:https://doi.org/10.5194/gmd-9-1937-2016
Fasullo JT, Otto-Bliesner BL, Stevenson S (2018) ENSO's changing influence on temperature, precipitation, and wildfire in a warming climate. Geophys Res Lett. doi:https://doi.org/10.1029/2018G L079022

Folland CK, Palmer TN, Parker DE (1986) Sahel rainfall and worldwide sea temperatures, 1901-85. Nature 320:602

Foltz GR, Brandt P, Richter I et al (2019) The tropical atlantic observing system. Front Mar Sci 6:206. doi:https://doi.org/10.3389/ fmars.2019.00206

Fontaine B, Roucou P, Monerie P-A (2011) Changes in the African monsoon region at medium-term time horizon using 12 AR4 coupled models under the A1b emissions scenario. Atmos Sci Lett 12. https://doi.org/10.1002/asl.321

Gaetani M, Flamant C, Bastin S et al (2017) West African monsoon dynamics and precipitation: the competition between global SST warming and $\mathrm{CO}_{2}$ increase in CMIP5 idealized simulations. Clim Dyn 48:1353-1373. doi:https://doi.org/10.1007/s0038 2-016-3146-z

Gettelman A, Hannay C, Bacmeister JT et al (2019) High climate sensitivity in the Community Earth System Model Version 2 (CESM2). Geophys Res Lett 46:8329-8337. doi:https://doi. org/10.1029/2019GL083978 doi

Giannini A, Salack S, Lodoun T et al (2013) A unifying view of climate change in the Sahel linking intra-seasonal, interannual and longer time scales. Environ Res Lett 8:24010. doi:https://doi. org/10.1088/1748-9326/8/2/024010

Han F, Cook KH, Vizy EK (2019) Changes in intense rainfall events and dry periods across Africa in the twenty-first century. Clim Dyn. doi:https://doi.org/10.1007/s00382-019-04653-z

Held IM, Soden BJ (2006) Robust Responses of the Hydrological Cycle to Global Warming. J Clim 19:5686-5699. doi:https://doi. org/10.1175/JCLI3990.1

Hoerling M, Hurrell J, Eischeid J, Phillips A (2006) Detection and attribution of Twentieth-Century Northern and Southern African Rainfall Change. J Clim 19:3989-4008. doi:https://doi. org/10.1175/JCLI3842.1

Hwang Y-T, Frierson DMW (2013) Link between the double-Intertropical Convergence Zone problem and cloud biases over the Southern Ocean. Proc Natl Acad Sci 110:4935-4940. https://doi. org/10.1073/pnas.1213302110

James R, Washington R, Jones R (2015) Process-based assessment of an ensemble of climate projections for West Africa. J Geophys Res Atmos 120:1221-1238. doi:https://doi.org/10.1002/2014J D022513 doi

Kent C, Chadwick R, Rowell DP (2015) Understanding uncertainties in future projections of seasonal tropical precipitation. J Clim 28:4390-4413. doi:https://doi.org/10.1175/JCLI-D-14-00613.1

Lee J-Y, Wang B (2014) Future change of global monsoon in the CMIP5. Clim Dyn 42:101-119. doi:https://doi.org/10.1007/s0038 2-012-1564-0

Liebmann B, Bladé I, Kiladis GN et al (2012) Seasonality of African precipitation from 1996 to 2009. J Clim 25:4304-4322. doi:https ://doi.org/10.1175/JCLI-D-11-00157.1

Lélé MI, Leslie LM, Lamb PJ (2015) Analysis of low-level atmospheric moisture transport associated with the West African Monsoon. J Clim 28:4414-4430. doi:https://doi.org/10.1175/JCLID-14-00746.1

Ma J, Chadwick R, Seo K-H et al (2018) Responses of the tropical atmospheric circulation to climate change and connection to the hydrological cycle. Annu Rev Earth Planet Sci 46:549-580. doi:https://doi.org/10.1146/annurev-earth-082517-010102

Ma J, Xie S-P, Kosaka Y (2011) Mechanisms for tropical tropospheric circulation change in response to global warming. J Clim 25:2979-2994. doi:https://doi.org/10.1175/JCLI-D-11-00048.1 
Martin ER, Thorncroft CD (2014) The impact of the AMO on the West African monsoon annual cycle. Q J R Meteorol Soc 140:31-46. doi:https://doi.org/10.1002/qj.2107

Masson D, Knutti R (2011) Climate model genealogy. Geophys Res Lett. https://doi.org/10.1029/2011GL046864

Mohino E, Janicot S, Bader J (2011) Sahel rainfall and decadal to multi-decadal sea surface temperature variability. Clim Dyn 37:419-440. doi:https://doi.org/10.1007/s00382-010-0867-2

Monerie P-A, Fontaine B, Roucou P (2012) Expected future changes in the African monsoon between 2030 and 2070 using some CMIP3 and CMIP5 models under a medium-low RCP scenario. J Geophys Res Atmos. https://doi.org/10.1029/2012JD017510

Monerie P-A, Oudar T, Sanchez-Gomez E (2018) Respective impacts of Arctic sea ice decline and increasing greenhouse gases concentration on Sahel precipitation. Clim Dyn doi. https://doi. org/10.1007/s00382-018-4488-5

Monerie P-A, Robson J, Dong B et al (2019) Effect of the Atlantic multidecadal variability on the global monsoon. Geophys Res Lett 46:1765-1775. doi:https://doi.org/10.1029/2018GL080903 doi

Monerie P-A, Roucou P, Fontaine B (2013) Mid-century effects of climate change on African monsoon dynamics using the A1B emission scenario. Int J Climatol. https://doi.org/10.1002/joc.3476

Monerie P-A, Sanchez-Gomez E, Boé J (2016) On the range of future Sahel precipitation projections and the selection of a sub-sample of CMIP5 models for impact studies. Clim Dyn doi. https://doi. org/10.1007/s00382-016-3236-y

Monerie P-A, Sanchez-Gomez E, Pohl B et al (2017) Impact of internal variability on projections of Sahel precipitation change. Environ Res Lett 12:. doi:https://doi.org/10.1088/1748-9326/aa8cda

Neelin JD, Münnich M, Su H et al (2006) Tropical drying trends in global warming models and observations. Proc Natl Acad Sci 103:6110-6115. https://doi.org/10.1073/pnas.0601798103

O'Neill BC, Tebaldi C, van Vuuren DP et al (2016) The Scenario Model Intercomparison Project (ScenarioMIP) for CMIP6. Geosci Model Dev 9:3461-3482. doi:https://doi.org/10.5194/ gmd-9-3461-2016

Palmer TN (1986) Influence of the Atlantic, Pacific and Indian Oceans on Sahel rainfall. Nature 322:251

Park J-Y, Bader J, Matei D (2015) Northern-hemispheric differential warming is the key to understanding the discrepancies in the projected Sahel rainfall. Nat Commun 6:5985

Park J, Bader J, Matei D (2016) Anthropogenic Mediterranean warming essential driver for present and future Sahel rainfall. Nat Clim Change 6:941-945

Richter I, Xie S-P, Wittenberg AT, Masumoto Y (2012) Tropical Atlantic biases and their relation to surface wind stress and terrestrial precipitation. Clim Dyn 38:985-1001. doi:https://doi.org/10.1007/ s00382-011-1038-9

Rockström J, Folke C, Gordon L et al (2004) A watershed approach to upgrade rainfed agriculture in water scarce regions through Water System Innovations: an integrated research initiative on water for food and rural livelihoods in balance with ecosystem functions. Phys Chem Earth Parts A/B/C 29:1109-1118. doi:https ://doi.org/10.1016/j.pce.2004.09.016

Roehrig R, Bouniol D, Guichard F et al (2013) The present and future of the West African Monsoon: a process-oriented assessment of CMIP5 simulations along the AMMA transect. J Clim 26:64716505. doi:https://doi.org/10.1175/JCLI-D-12-00505.1

Rowell DP (2012) Sources of uncertainty in future changes in local precipitation. Clim Dyn 39:1929-1950. doi:https://doi.org/10.1007/ s00382-011-1210-2

Rowell DP, Chadwick R (2018) Causes of the uncertainty in projections of Tropical Terrestrial Rainfall Change: East Africa. J Clim. doi:https://doi.org/10.1175/JCLI-D-17-0830.1

Rowell DP, Folland CK, Maskell K et al (1992) Modelling the influence of global sea surface temperatures on the variability and predictability of seasonal Sahel rainfall. Geophys Res Lett 19:905-908. doi:https://doi.org/10.1029/92GL00939 doi

Santer BD, Taylor KE, Gleckler PJ et al (2009) Incorporating model quality information in climate change detection and attribution studies. Proc Natl Acad Sci 106:14778-14783. https://doi. org/10.1073/pnas.0901736106

Schneider U, Becker A, Finger P et al (2014b) GPCC's new land surface precipitation climatology based on quality-controlled in situ data and its role in quantifying the global water cycle. Theor Appl Climatol 115:15-40. doi:https://doi.org/10.1007/s0070 4-013-0860-x

Schneider T, Bischoff T, Haug GH (2014a) Migrations and dynamics of the intertropical convergence zone. Nature 513:45

Seager R, Liu H, Henderson N et al (2014) Causes of Increasing Aridification of the Mediterranean Region in Response to Rising Greenhouse Gases. J Clim 27:4655-4676. doi:https://doi. org/10.1175/JCLI-D-13-00446.1

Shekhar R, Boos WR (2017) Weakening and shifting of the Saharan Shallow Meridional Circulation during Wet Years of the West African Monsoon. J Clim 30:7399-7422. doi:https://doi. org/10.1175/JCLI-D-16-0696.1

Sidibe M, Dieppois B, Eden J et al (2020) Near-term impacts of climate variability and change on hydrological systems in West and Central Africa. Clim Dyn 54:2041-2070. doi:https://doi.org/10.1007/ s00382-019-05102-7

Solomon S, Qin D, Manning M et al (2007) Climate change 2007the physical science basis: Working group I contribution to the fourth assessment report of the IPCC. Cambridge University Press, Cambridge

Stanzel P, Kling H, Bauer H (2018) Climate change impact on West African rivers under an ensemble of CORDEX climate projections. Clim Serv 11:36-48. doi:https://doi.org/10.1016/j.clise r.2018.05.003

Sultan B, Gaetani M (2016) Agriculture in West Africa in the TwentyFirst Century: climate change and impacts scenarios, and potential for adaptation. Front Plant Sci 7:1262. doi:https://doi.org/10.3389/ fpls.2016.01262

Sultan B, Guan K, Kouressy M et al (2014) Robust features of future climate change impacts on sorghum yields in West Africa. Environ Res Lett 9:104006. doi:https://doi.org/10.1088/17489326/9/10/104006

Sylla MB, Faye A, Klutse NAB, Dimobe K (2018) Projected increased risk of water deficit over major West African river basins under future climates. Clim Change 151:247-258. doi:https://doi. org/10.1007/s10584-018-2308-x

Sylla MB, Giorgi F, Pal JS et al (2015) Projected changes in the annual cycle of high-intensity precipitation events over West Africa for the late Twenty-First Century. J Clim 28:6475-6488. doi:https:// doi.org/10.1175/JCLI-D-14-00854.1

Taylor KE, Stouffer RJ, Meehl GA (2012) An overview of CMIP5 and the experiment design. Bull Am Meteorol Soc 93:485-498

Xie S-P, Deser C, Vecchi GA et al (2015) Towards predictive understanding of regional climate change. Nat Clim Chang 5:921

Yan Y, Lu R, Li C (2018) Relationship between the future projections of Sahel Rainfall and the simulation biases of present South Asian and Western North Pacific Rainfall in Summer. J Clim 32:13271343. doi:https://doi.org/10.1175/JCLI-D-17-0846.1

Zappa G, Shepherd TG (2017) Storylines of atmospheric circulation change for European Regional climate impact assessment. J Clim 30:6561-6577. doi:https://doi.org/10.1175/JCLI-D-16-0807.1

Publisher's Note Springer Nature remains neutral with regard to jurisdictional claims in published maps and institutional affiliations. 